\title{
Artículos
}

\section{El desafío de reconstruir una nueva idea de socialismo}

\author{
Iosu Perales Arretxe
}

\section{Resumen}

La palabra socialismo plantea hoy bastantes problemas. La izquierda ha empobrecido su horizonte, incluso, duda de su propio proyecto histórico porque hasta el momento no ha podido proponer, de manera exitosa, un paradigma distinto que no sea el que corresponde a la socialdemocracia de la Internacional Socialista. En este sentido, la izquierda debe reconocer que sus rutas son torcidas y reconstruir su proyecto político a partir de una reflexión autónoma y de los datos más que de una ideología.

\section{Introducción}

A lo largo de este siglo que termina, en la izquierda ha predominado la idea de un camino recto, dividido en etapas, hacia el socialismo. Y es que en la izquierda la tentación de situarse en las coordenadas del progreso, como si éste fuera un aliado cómplice de las aspiraciones de liberación, ha tenido un peso mayoritario. Pero ni el progreso puede presentar un balance limpio que demuestre que lo es, ni en todo caso sus coordenadas tienen una simpatía especial por las izquierdas.
El acoso a que se ve sometida la izquierda por los poderes reales del mundo de hoy se une a una crisis discursiva y de propuestas, todo lo cual da como resultado, por primera vez, una seria duda acerca de la marcha de la historia.

En estas circunstancias desconocidas hasta ahora, en la izquierda hay con frecuencia dos tentaciones igualmente arriesgadas: una de ellas es la del quietismo, la otra la de escapar rápidamente en dirección a la derecha en busca de un lugar seguro. El quietismo conduce a la retórica, al revoluciona- 
rismo de lenguaje que ignora por completo las reglas del juego al considerarlas trucadas, y que al menospreciarlas queda fuera de toda posibilidad de intervenir con eficacia en el cambio de sociedad. $\mathrm{Y}$, alejarse del campo de batalla con el argumento de que todo, parlamento, prensa, leyes, etc, está infestado de tiburones conservadores, significa quedarse en un escenario imaginario en el que nada se dilucida. En el lado contrario, los movimientos hacia la derecha resultan patéticos, pues parecen buscar el aplauso de las fuerzas económicas y políticas más poderosas, bajo la ingenua creencia de que el porvenir en justicia, sin explotación, puede ser pactado.

En el marco de estos movimientos mutantes se produce una catarsis antes impensable: de pronto el pasado de lucha es un gran equívoco y se empieza a cuestionar si de verdad hay diferencia entre izquierda y derecha. En los movimientos hacia la derecha hay un querer ser como ellos, algo pocas veces reconocido explicítamente, pero que sin duda impulsa en una dirección en la que la izquierda puede terminar, sin más, siendo la otra mano de la derecha. No hay que olvidar que el mayor triunfo de la derecha se da cuando fabrica su propia oposición.

Por alguna maldición parece sumamente complicado que haya una izquierda que entienda y asuma que sus rutas son torcidas, y que debe proceder a una reconstrucción de su proyecto político a partir de una reflexión autónoma y de los datos más que de una ideología, o de la adscripción a una corricnte política internacional que cree tener todas las respuestas. En realidad, la izquierda de occidente está prisionera de una tradición racionalista que desde Platón hasta Marx se ha apoyado en el dogma de que todo problema auténtico sólo puede tener una solución verdadera, así como en la creencia de que lodas las soluciones deben formar un lodo armónico en un saber omnicomprensivo.

Sin embargo, no es malo empezar por reconocer que hoy la izquierda no tiene una teoría de la revolución; ninguna de las del siglo XIX funciona. Hay que pensar no en una teoría sino en líneas que excluyen cuadros de explicación total. Se trata de repensar numerosas cuestiones desde la conciencia de que las rutas del cambio son necesariamente torcidas.

La palabra socialismo necesita ser desnudada para, superando el mito y la excesiva simplifica- ción del lenguaje, hacer referencia a qué comunidad queremos, qué sociedad queremos, qué mundo habitable queremos. A fin de cuentas, se trata de las grandes interrogantes que deberían mover a la pasión de pensar y actuar. $Y$, sin embargo, sucede a menudo que en la izquierda se prefiere no aceptar el desafío de encontrar las respuestas por el temor a que resulten ser excesivamente comprometidas.

En cualquier caso, ya no se trata de ofrecer soluciones, sino de aportar ideas y criterios innovadores que ayuden a la izquierda a renovarse desde la crítica a lo existente -que desde luego no es el mejor de los mundos. De manera que entre la renuncia y la renovación elegimos esta última. Puesto que renuncia es también quedarse en la nostalgia viendo pasar el mundo.

\section{Una izquierda perpleja}

Es difícil evaluar el alcance de la actual conmoción que sufren tantas gentes de izquierda sin hacer referencia a esa psicología que viene del movimiento socialista de principios de siglo. En ella ocupó un lugar principal el rechazo de lo complejo, la búsqueda de verdades sencillas y de líneas de pensamiento armoniosas. La convicción de que la historia avanza inevitablemente en la buena dirección y la creencia de que el progreso técnico lleva consigo el progreso social eran dos principios básicos de su ideología.

La mentalidad de la izquierda ha estado muy impregnada por la seguridad de que los hechos acabarán por darnos la razón. La fe en el triunfo final le otorgaba un mundo seguro, aunque la lucha fuera terrible y en ella perdieran la vida muchas personas. Así, la actividad de la izquierda, por modesta y limitada que fuese, surgía como parte de un curso transcendente.

Las creencias socialistas en el triunfo final han sido, durante gran parte de este siglo, un factor de cohesión y entusiasmo. Muchas gentes del pueblo, obreros y campesinos, estudiantes, mujeres y jóvenes, sc unían a los partidos de izquierda contagiadas por ese ambiente optimista.

En la formación de los grandes movimientos de izquierda luvo una importancia decisiva la revolución rusa de octubre de 1917. El nuevo régimen brindaba una referencia viva y dio a millones de personas la posibilidad de saborear un éxito que 
su propia experiencia les negaba. Nació, a gran escala, un movimiento de identificación con un sistema político, en realidad poco conocido y muy idealizado, al que se hizo depositario de los anhelos socialistas.

Las victorias de Cuba y Vietnam favorecieron el desarrollo de movimientos revolucionarios de nuevo tipo, más radicalizados políticamente, más innovadores en las formas de lucha. Pero ello no propició una actitud crítica de fondo al mundo seguro, teóricamente conformista, que estaba instalado en la izquierda. El desmoronamiento de los países del este de Europa a finales de los ochenta suscitó angustia en buena parte de la izquierda. La seguridad se tornó inseguridad. Para millones de personas en el mundo, el desplome de la Unión de Repúblicas Socialistas Soviéticas supuso un desgarramiento interior, una cruel derrota que golpeó sus vidas. De pronto, una sensación de orfandad se apoderó de la izquierda.

En los últimos años, el descrédito del socialismo como sistema es algo vinculado a la experiencia principalmente soviética. $\mathrm{Y}$, significativamente, la izquierda mundial no ha sabido o podido hasta cl momento proponer de manera exitosa un paradigma socialista distinto que no sea el que corresponde a la socialdemocracia de la Internacional Socialista, paradigma que cohabita con el capitalismo. Peor todavía, parece que hablar de socialismo es regresar a lo viejo, a lo inviable.

Ciertamente, la palabra socialismo plantea hoy bastantes problemas. Designa al mismo tiempo a los regímenes de Europa del este y a la socialdemocracia del oeste. No es fácil para el gran público asociar la palabra socialismo a una sociedad nunca realizada, más igualitaria, justa, libre y democrática. Esta dificultad está interiorizada en la propia izquierda al haberse producido una fragmentación en su pensamiento. La visión holística predominante durante más de un siglo hacía posible encajar cada acto, cada sacrificio, cada conquista social, en un proyecto intelectual y político que daba un sentido finalista, una confianza insustituible de estar recorriendo el trayecto correcto. Ahora, cada acto, cada lucha, aparece dislocado de un proyecto final, y la visión atomística tiende a concentrarse en lo concreto, en lo puntual, en lo local.

Así nos encontramos con una izquierda que ha empobrecido su horizonte y que, incluso, duda de su propio proyecto histórico. La duda conduce con frecuencia a dejarlo de lado, sin decirlo expresamente, y a buscar en los movimientos tácticos y las luchas a corto plazo una nueva razón de ser. Sin embargo, la idea de socialismo, por oposición a la de capitalismo, sigue evocando un cambio global de sociedad. Una nueva sociedad no movida por los principios filosóficos e ideológicos del liberalismo, y que esté inspirada por el ideal de la comunidad de bienes aun cuando esta idea esté cargada de problemas.

Reivindicar la palabra socialismo para nombrar una descripción que apunta hacia lo que no existe plantea a la izquierda el desafío de llenarla de nuevo contenido. Desde luego, quitarse de encima la palabra no resuelve el problema de su dificultad; puede dar la comodidad de despojar a la izquierda de un complejo de culpa, muy probablemente al precio de perder su naturaleza y razón de ser.

La palabra nieve tiene para los esquimales cincuenta significados diferentes, y algo de esto pasa con la palabra socialismo. La izquierda con vocación revolucionaria debe encontrarle el sentido que mejor se ajuste a una actitud crítica y no complaciente. En todo caso, la palabra debe corresponder a esa voluntad transformadora de lo global, sin lo cual parece imposible hacer resurgir una conciencia de oposición a lo existente en la sociedad neoliberal.

A las puertas del siglo XXI, como bien dice el pensador italiano Paolo Flores, la izquierda no tiene nuevos objetivos que descubrir. Libertad, igualdad, solidaridad, justicia, propuestas revolucionarias básicas para una nueva sociedad, no resultan obvias. Se trata de pretenderlas en serio, por encima de los avatares tácticos, y de desarrollar e incluso inventar una práctica adecuada que nos acerque a esos propósitos. Son valores en los que late

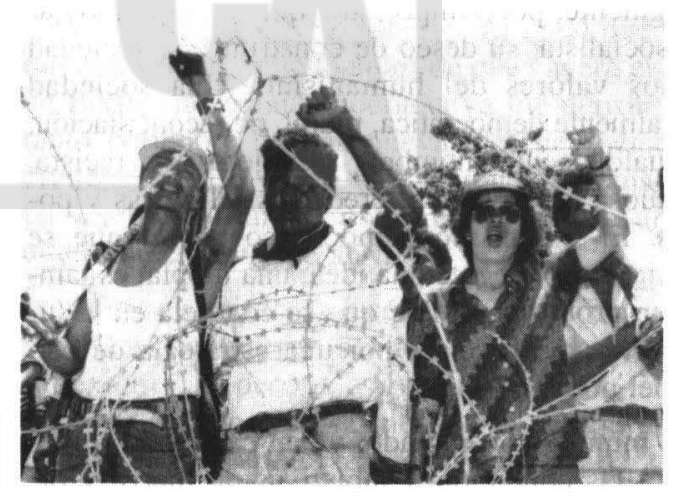


un impulso crítico al capitalismo en cualquiera de sus versiones y una voluntad transformadora.

Para enfrentar los cambios hacia una nueva sociedad se necesita ajustar las ideas, renovarlas en buena parte, teniendo como punto de partida e inspiración los valores de la izquierda nacidos como oposición a toda forma de opresión y explotación, cuya sustancia es primeramente moral.

Es verdad que en el pasado la izquierda hizo una construcción ideológica de la realidad que no se ajustaba a los hechos. También tenía un diseño del poder revolucionario que ahora revisamos y encontramos inviable e incorrecto, sobre todo por sus perfiles excluyentes y autoritarios. Pero la autocrítica en el ámbito de las ideas no debe echar el agua sucia por la cañería y además al niño. Una inclinación frecuente en la izquierda es la de moverse como el péndulo de un reloj, y pasar de unos dogmas a otros de signo opuesto. No debemos dejarnos conducir por un espíritu derrotista de mirar hacia el pasado y ver en él dos o tres décadas perdidas repletas de fracasos; no debemos ceder a la tentación de convertir el pragmatismo en el núcleo de una nueva doctrina que promete el cielo a cambio de aceptar las bases del sistema económico y político dominante. En circunstancias adversas, la tendencia a adaptarse de parte de la izquierda lo conduce a elaborar discursos que resulten simpáticos a los adversarios de la derecha política y económica. Gana terreno la inclinación al pragmatismo como nueva doctrina; el ir resolviendo el día a día y la menor preocupación por la perspectiva y el estudio de los problemas complejos.

Sin embargo, el sentido de la izquierda, su razón de ser descansa en el hecho de que es la esperanza para contribuir al logro de una sociedad no sólo algo mejor a la actual sino distinta. No es, por consiguiente, poco importante que afirme su vocación socialista, su deseo de construir una sociedad con los valores del humanismo. Una sociedad integralmente democrática, plural, de reconciliación, de igualdad entre hombres y mujeres, no racista, respetuosa con todas las creencias religiosas y polílicas. El socialismo democrático por el que se lucha no es solamente una idea, una utopía; es también un proyecto posible que se concreta en la lucha política y que pasa por una estrategia de disputa del poder.

El mundo ha cambiado, y han cambiado sobremanera las condiciones subjetivas de fuerza y or- ganización y expectativas de triunfo de la izquierda. Estos cambios han sido interpretados por algunos analistas como el fin de las expectativas revolucionarias y el inicio de un período de colaboración entre derecha e izquierda para conseguir lo posible. Coherentes con este pensamiento, algunos dirigentes de izquierda, ideológicamente huérfanos ante las inaccesibles uvas en la parábola de Esopo, se autoconvencen de que ya no es de su gusto lo que hasta ayer había motivado su lucha, y adoptan como nuevas y apetecibles las viejas ideas del sistema imperante.

Esta no es la manera justa de abordar una más que necesaria renovación conceptual y política. La izquierda nació con una vocación civilizatoria y con esa vocación debe enfrentar el final del siglo, sin que ello signifique dejar a un lado concertaciones y pactos cuando ello convenga a los intereses de las mayorías. De modo que el ejercicio de cambios en lo ideológico nada tiene que ver con desnaturalizar el carácter de izquierda, su actitud atenta revolucionaria, sus convicciones democráticas. En cambio, sí liene como objeto combatir planteamientos impropios de una izquierda que lucha por el socialismo democrático a finales del siglo $\mathrm{XX}$.

Debemos tomar en cuenta el veredicto de la historia en cuanto a concepciones y políticas que habiendo sido parte del ideario de la izquierda, han demostrado ser erróneas. Hemos de evitar sustituir unos conceptos absolutos por otros igualmente absolutos. Es conveniente identificar el carácter abierto que deben conservar muchas ideas y criterios, en la medida en que la experiencia y el tiempo van asignando lo acertado o erróneo de muchas de ellos. Pero también es verdad que la izquierda requiere de inspiraciones y criterios sólidos que constituyen una parte de su razón de ser. El reto es encontrar el necesario equilibrio entre fundamentos e hipótesis, entre principios y criterios relativos.

Sin duda, el momento en que vivimos nos pide una actitud de remover las aguas, el reverso de la comodidad y del remanso intelectual. Nos exige aceptar que el futuro es inseguro, no comprobable. y que lejos de cerrar el círculo hay que abrirlo. Este ejercicio de la razón nos invita a desarrollar una fuerza espiritual e intelectual, una potencia crítica a todo lo existente, una actitud de investigación y debate. Nuestra ventaja es que ahora sabemos más que antes. 
Pero más que nunca necesitamos asimismo de algo que reclamaba el peruano José Carlos Mariátegui: la lucrza de la pasión, la ambición de cambiar la vida. Esta es la actitud con la que hemos de rellexionar y discutir una nueva idea del socialismo.

\section{Nueva idea del socialismo}

Ralph Miliban tenía toda la razón: El socialismo no es inevitable, ni es por consiguiente el resultado seguro de las contradicciones que vive el capitalismo. Es, nada más y nada menos, una posibilidad. Al igual que son una posibilidad futura nucvas regresiones $y$ peores catástrofes. El socialismo surge como lo deseable en medio de la amenaza permanente de situaciones tenebrosas. Baste decir que los socialistas de linales del siglo pasado nunca imaginaron hasta que punto el siglo $\mathrm{XX}$ se convertiría en un gran matadero. El holocausto nazi y el gulag estalinista nos dan la medida de una naturaleza humana que invita a dudar seriamente de que la historia camine en el sentido optimista de Kant.

Y no se trata ahora de sustituir una concepción optimista de la historia por otra pesimista de igual peso. De lo que se trata es de concebir la vida como una batalla permanente -en palabras de Norman Geras-. superando todo pensamiento complaciente con el llamado progreso. Durante décadás, partidos comunistas en todo el mundo han vivido de las rentas de creer que serían dueños del futuro como consecuencia de la esperada crisis fatal del sistema capitalista. Esta ideología, conservadora, que predecía el triunfo final es la que se ha venido abajo. En adelante, todo es más incierto y dependerá de nuestra lucha; la historia es una construcción humana, no un movimiento autónomo con fínal feliz, no una rueda de luces desplegándose luminosa hacia el futuro, afirma Geras.

Tal vez, además, sea deseable apostar por utopías más modestas que por una sociedad armoniosa. Y no porque sea malo pensar en una gran ulopía -magnífico ejercicio del imaginario-, sino porque no es necesario saber si será posible para esta humanidad estar convencidos de que debemos luchar para poner remedio a males actuales que lesionan gravemente la condición humana. Luchar por la igualdad y justicia sin saber cuánto podremos lograr, constituye una aventura moral de inspiración netamente revolucionaria.

El desafío de una nueva idea de socialismo no es meramente intelectual. Al contrario, al ser sólo una posibilidad invita a una actitud de lucha sin fin, que es lo que en definitiva es. De manera que la sustitución de una visión armoniosa por utopías más modestas, lejos de ser un factor desmovilizador es exactamente lo opuesto: una rebelión cotidiana frente al espanto del neoliberalismo, en la medida que se proponen cambios estructurales e institucionales, aun a riesgo de ser helerodoxos con el gran discurso ideológico. Basta saber que sin esos cambios las injusticias permanecerán.

Es verdad que en estos momentos de dificultad para la izquicrda, en lugar de elegir una actitud de experimentación y búsqueda, hay quienes prefieren refugiarse en un pragmatismo a ultranza y en el posibilismo más acentuado. Semejante refugio ofrece nuevas seguridades, un discurso aparentemente eficaz y algunas victorias parciales. Por lo se que ve hay en la izquierda sectores que no pueden permanecer en un territorio de independencia, tensión y búsqueda; necesitan practicar alguna religión en una nueva iglesia. Pero quienes dan ese paso tal vez no han pensado bien en el hecho de que la socialdemocracia, como encarnación de la adaptación más exitosa de la izquierda, acepta los fundamentos del capitalismo, su funcionamiento, sus valores liberales levemente corregidos. $O$ puede ser que prefieran no saberlo. Al igual que ignoran una verdad: mucho antes de que cayera el muro de Berlín, la socialdemocracia ya fue derrotada en tanto portadora de una nueva idea de sociedad y civilización. Lo cierto es que muchos tránsfugas, tal vez por cansancio, prefieren cerrar nuevamente el círculo en lugar de abrirlo.

Abrir el círculo es incómodo. Lo es por cuanto significa acentuar un sentido crítico, fortalecer la reflexión y el debate, volver a empezar —una y otra vez. Supone precisamente una actitud revolucionaria frente a toda tentación conservadora de la propia izquierda. Abrir el círculo significa, volvien- 
do a los valores de libertad, igualdad, solidaridad y justicia, comprender que los mismos están en permanente colisión. No parece factible, con esta humanidad, conseguir una armonía entre todos ellos; pero debemos aspirar al mejor equilibrio posible. Así, por ejemplo, la libertad e igualdad colisionan si se desarrollan hasta las últimas consecuencias. Isaiah Berlin afirmaba que estamos condenados a elegir y que cada elección puede entrañar una pérdida irreparable. Tal vez su punto de vista sea extremo y demasiado pesimista, pero la consecuencia última de esta comprensión es nuevamente revolucionaria pues nos dice que la historia es conflicto y proyecto inacabado. Habrá quien contemple esta posibilidad desde una conciencia trágica, al descubrir que la especie humana está condenada a la imperfección. Parece más atractiva una ética de la alegría, ya que en la imperfección se encuentra un viaje de la conciencia lleno de incertidumbres que nos invitan a ser constructores verdaderos de la historia humana.

Ahora bien, la incertidumbre presente y futura, el socialismo como posibilidad y la superación de toda visión armónica de la lucha, no debilita para nada la fuerza moral y política del socialismo. Lo que debilitó a la izquierda fue justamente lo contrario: el creerse poseedora del futuro y conocedora de todas las soluciones. Esta creencia fue doblemente dañina: en primer lugar, por ilusoria y, en scgundo término, porque desconsideró profundizar sobre problemas de los que, en realidad, sólo sabíamos cl enunciado.

El socialismo está vivo a condición de que se presente como alternativa humanista que propone no tan sólo un mejor reparto de los bienes, sino una nueva civilización, unas nuevas relaciones sociales y sentimentales, una nueva estructura política que impulse la participación política ciudadana mucho más allá del voto cada equis años.

Dice bien la nicaragüense Mónica Baltodano al señalar que en la fuerza del capitalismo está su gran debilidad. Ciertamente, el avance totalitario del libre mercado está configurando un mundo básicamente dual: una minoría satisfecha que no entiende de equidad; y una mayoría de hombres y mujeres a merced de esa bomba de la pobreza que es el neoliberalismo. La lógica de este sistema es que no es posible lo primero sin lo segundo, y en ello radica su fragilidad.

Por ello la izquierda no debe arrugarse al escu- char los himnos del capitalismo. El futuro está abierto, también para el socialismo. Lo que hace falta es: no transigir en los principios y saber enriquecerlos a contracorriente, en la confianza de que los malos tiempos ya pasarán.

\section{Optimismo infundado del marxismo}

Que el futuro está abierto quiere decir que no es posible capturarlo como pensaba el marxismo más extendido. Haciendo analogía con el paso del feudalismo al capitalismo, teóricos e ideólogos marxistas consideraban una ley histórica el paso del capitalismo al socialismo. Se había extendido en la izquierda un optimismo injustificado.

El hilo conductor de la historia, las fuerzas productivas, aseguraba una línea ascendente y señalaba al futuro como un aliado de la emancipación social. Esta concepción aseguraba que el desarrollo acelerado del capitalismo nos acercaba a su fin; que el progreso tecnológico era necesariamente un hecho favorable y que la extensión de la clase obrera lo convertía en una fuerza liberadora. El enfoque predictivo otorgaba una seguridad intelectual y al mismo tiempo sectarismo; contenía una idea unilateral e ingenua del discurrir de la historia en un solo sentido posible.

Ese marxismo suminitró a millones de personas una fe, una conciencia de superioridad en relación con las fuerzas contrarias o competidoras dentro del movimiento obrero. Sirvió para diferenciar el propio campo de los partidos comunistas y alimentar la unidad interna, reforzando un sentido de pertenencia.

Pero una ideología que vive de predecir el triunfo final depende del éxito de sus predicciones. La izquierda esperaba en occidente, desde hace un siglo, una revolución que no ha llegado; la clase obrera que emergió en el siglo pasado como la gran fuerza social revolucionaria, no parece haber estado a la altura de aquellas esperanzas; el sistema capitalista no ha sido derrotado como consecuencia de sus propias contradicciones, al menos todavía; los estados de Europa del este que proclamaron ser la encarnación de los ideales marxistas han resultado ser poco atractivos, han sido represivos, antidemocráticos y poco eficaces. Como consecuencia de todo ello, el socialismo sufre un serio revés, queda desprestigiado ante la gente corriente y aun entre los sectores interesados en una alterna- 
tiva al capitalismo, y se debilita como paradigma.

La corriente llamada científica, que se popularizó con la revolución soviética, subestimó la cuestión moral y la situó como un simple subproducto de la lucha de clases. La voluntad humana sólo debía dejarse llevar por el río hegeliano de la historia que avanza en el único sentido posible. El socialismo parecía una meta segura.

A finales del siglo $\mathrm{XX}$, la vigencia del socialismo descansa principalmente en otros principios y valores: es deseable y necesario. El fundamento de nuestra aspiración socialista es primero de orden moral porque se apoya en la voluntad de acabar con la injusticia y la desigualdad, en el odio a toda forma de opresión. La investigación científica puede ayudar a la voluntad a encontrar la forma de alcanzar sus propósitos, pero no puede decidir sus fïnes. La política es el medio del que nos valemos para alcanzar nuestro propósito. La lucha por el socialismo necesita de un cuadro de valores que inspiren la crítica de lo existente y la acción por transformar la realidad.

La vida del socialismo adquiere ahora, a diferencia del pasado, una nueva dimensión más abierta y por ello más dilícil de admitir. Veamos lo que dice la socióloga británica Rosemary Crompton. "La ausencia de políticas revolucionarias de la clase obrera refleja que no existe correspondencia necesaria entre la economía y la política; es decir, entre la situación económica de la clase y la acción política".

"No existe una relación privilegiada o necesaria entre la clase obrera y el socialismo, por lo que cl movimiento socialista puede constituirse de forma independiente de la clase, aunque con la clase". "El socialismo entraña metas humanas universales que transcienden el carácter estricto de los intereses materiales de clase, por lo que puede dirigirse a un público más amplio".

Estas tres puntualizaciones de Crompton significan un cambio profundo que supera la idealización de la clase obrera y una lectura sectaria del proyecto socialista.

\section{El futuro que ignoramos}

No se trata de diseñar el socialismo como un arquitecto diseña un edificio al detalle. La experiencia de los procesos revolucionarios en distintas partes del mundo y, en particular, el fracaso de los regímenes de Europa oriental desaconseja las pretensiones, muy frecuentes en la cultura de la izquierda, de elaborar una formulación teórica, anticipada y de bastante detalle del socialismo. Es bueno imaginar la sociedad deseable, sobre todo porque ayuda a desarrollar el sentido de la crítica a lo que ya existe. Pero si no se tiene conciencia de las profundas limitaciones de ese ejercicio imaginativo, si terminamos creyendo que es posible tener un modelo pormenorizado de la sociedad del futuro, y además pretendemos basarla en fundamentos de orden científico, nos encerraremos en un mundo teórico, abstracto, nada comprobado, que nos suministrará la ilusión de poseer la sociedad ideal. ¿Quién se atrevería hoy a definir cómo tiene que ser la economía en el socialismo, más allá de algunos criterios? La planificación burocrática ha fracasado; la planificación democrática no la conocemos; tampoco sabemos si una organización económica no capitalista puede resolver las tendencias gobernadas por el deseo ilimitado de beneficio particular, algo tan arraigado en los seres humanos y que explica el éxito del capitalismo.

Es más acertado plantear la cuestión de la sociedad futura admitiendo que es mucho lo que no sabemos ni podemos saber anticipadamente acerca de ella. Se trata de señalar trazos en lugar del dibujo perfecto, puntos de referencia hacia los cuales interesaría tender. Podemos ir definiendo los materiales para construir el edificio, aun cuando no podamos diseñarlo de una manera acabada. De todo ello pueden surgir alternativas de alcance medio, lo cual no es poca cosa.

Por ejemplo, podemos propugnar un máximo de igualdad social, pero ignoramos por completo cuánta igualdad podrá realizarse en la mejor de las hipótesis. Lo mismo puede decirse de otras aspiraciones. Si tratáramos de definir minuciosamente los objetivos, nos colocaríamos en una posición erra- 
da; lo probable es que terminaran revelándose de otro modo. Afortunadamente, el movimiento de la historia es lo suficientemente rico como para hacer variar cualquier hipótesis que pretenda conducir su curso.

El socialismo es una alternativa al capitalismo. Pero para que sea humano y de este mundo necesita deshacerse del mito de la propiedad. Frente al viejo socialismo que quiso hallar un foco universal de los males de la sociedad capitalista (y creyó encontrarlo en la propiedad privada), preferimos una visión apoyada en la crítica multilateral a la civilización actual, no sólo en su vertiente cconómica.

En este mismo sentido, es reveladora la reflexión de la sandinista Mónica Baltodano: "En la Nicaragua sandinista se llevaron a cabo radicales Iransfonmaciones cconómicas y políticas. En un país esencialmente agrario, haber democratizado la propiedad rural, entregando a los agentes del cambio la mitad de la tierra cultivable del país, no era poca cosa. Sin embargo, ello no pudo evitar que la conciencia del campesino, del ciudadano rural, siguiera empeñada por las cadenas del pasado. El universo subjetivo, el cspacio de los valores, el mundo de la cultura, continuó pagando el tributo de los esclavos: la sumisión y la dependencia del pasado. Ello se puso en evidencia en los reveses electorales del sandinismo en los años 90 y 96".

Tradicionalmente en la izquierda, la propiedad privada ha constituido el núcleo de la crítica al capitalismo. Hoy sabemos que la ausencia de propiedad privada no resuelve por sí sola todos los problemas. Tampoco es suficiente con expropiar y nacionalizar; ya que tales medidas no implican por sí mismas un control colectivo, democrático, ni una gestión con fines igualitarios. Sin embargo, como accrtadamente sugiere el pensador español Eugenio del Río, "no debemos abandonar la vieja inspiración socialista de la propiedad social de los medios de producción", aun cuando se hace necesaria una reflexión ajena a todo dogmatismo, que recoja las experiencias habidas y nos permita vislumbrar algunos criterios. Pero la propiedad social, precisamente, supone también propiedad privada en dislintas formas.

El planteamiento que hacía de la propiedad el foco del cambio social conectaba con la importancia central que dio el marxismo a la economía como lactor de arrastre fundamental para el cambio de la sociedad, dándole una dimensión economicista y de idealismo.

El libre mercado ha sido y es la base de un sistema económico explotador. Pero no sabemos si se podrá prescindir del mercado, al menos durante largo tiempo, en la construcción de una sociedad diferente. De la experiencia de algunos países sabemos que una economía estatizada no es eficaz y fuente de democracia. Pero aun cuando tenemos estas dos críticas, no sabemos lo suficiente para definir un modelo superior de organización de la economía. Consideramos útil, en todo caso, estos tres criterios del propio Eugenio del Rio, tanto en el orden de las ideas como para la implementación de experiencias económicas de signo popular: democracia en los métodos, en la organización; tendencialmente igualitaria en la distribución; y de resultados eficaces en su funcionamiento.

La experimentación nos podrá dar respuestas a las interrogantes y nos propondrá nuevas dificultades sobre las que habremos de reflexionar. En todo caso sí podemos afirmar que las necesidades de las grandes mayorías son incompatibles con el imperio de las multinacionales y del capital financiero.

En cl capitalismo no hay solución para las mayorías. Otra cosa es lo que plantea el siguiente problema: ¿Qué espíritu fuerte puede oponerse al motor económico del capitalismo? Hacer dinero, hacer negocios, es algo que en cinco siglos ha ido destruyendo a la humanidad y a la vez ha resultado muy eficaz. ¿Puede ser la solidaridad - la distribución justa- un motor económico en una nucva sociedad?

El problema del mercado es complejo. Si escogemos el mercado de los consumidores, y proclamamos el derecho y la libertad de la gente a adquirir los productos que más le interesan, en contra de un consumo dirigido por el Estado, parece obvio que ello determinaría el qué y el cuánto se produce. ¿Este mercado de los consumidores puede ser compatible con un sistema no movido por los principios capitalistas? En ese caso, ¿quién decidiría los precios? Una alternativa podría ser la combinación de la oferta y la demanda con la intervención reguladora del Estado. Sin embargo, ino lesionaría el intervencionismo estatal la llegada de productos al mercado?

Por otra parte, el mercado es también el mercado de la fuerza de trabajo. Este mercado de oferta y 
demanda de fuerza de trabajo es central en el capitalismo, y da lugar a la plusvalía, es decir, a la apropiación sistemática del excedente por parte de la propiedad de los medios de producción. En este hecho se basa la teoría de Marx sobre la explotación. ¿Este mercado de trabajo es compatible con la emancipación social? ¿Hay que revisar la concepción de Marx? Desde luego Marx hizo de la propiedad privada concentrada en una sola clase el reo institucional, el gran acusado, pero hemos visto cómo en sociedades donde la propiedad pasa a lítulo del Estado también se da el hecho de la explotación. Habría entonces que preguntarse lo siguiente: ¿Qué características e instituciones de una economía son esenciales para dar sentido a una concepción de la explotación en la entrada del siglo XXI? ¿Podemos pensar en una teoría de la explotación suficientemente general como para permitir incluso una definición en el caso de variables institucionales?

Al hablar del mercado nuevamente surge ante nosotros el problema de la propiedad, ahora desde un punto de vista del período en que nos encontramos. El analista y sociólogo nicaragüense Orlando Núñez advierte que la propiedad era el demonio de la izquierda, para indicar que la revolución sandinista ayudó, paradójicamente, a propietarizar la sociedad de Nicaragua, dando a amplios sectores populares, campesinos y urbanos, la posibilidad de hacerse con el control de medios de producción. Núñez reflexiona sobre la necesidad de superar la vieja dicotomía que hacía creer que la propiedad o bien era negativa o bien tenía que pasar al Estado. Abunda la idea de que si la propiedad es buena para el campesinado, bien sea en forma cooperativa, autogestionada o individual, lo es también para los obreros industriales.

Ciertamente, desde la izquierda se ha de hacer un esfuerzo por diferenciar la propiedad concentrada de terratenientes, monopolios y grandes empresarios, de la propiedad del pueblo, que es mucho más legítima, si es que se puede hablar de gradación.

En este sentido, se abre una línea de debate muy interesante en cuanto a la oportunidad de impulsar la propiedad popular, social, en el escenario del neoliberalismo. La cuestión sería entonces combinar la resistencia al neoliberalismo en todos los planos posibles y, al mismo tiempo, alentar el acceso a la propiedad de sectores del pueblo, campesinos y obreros, que en formas asociativas - vía más adecuada para competir en un escenario eco-

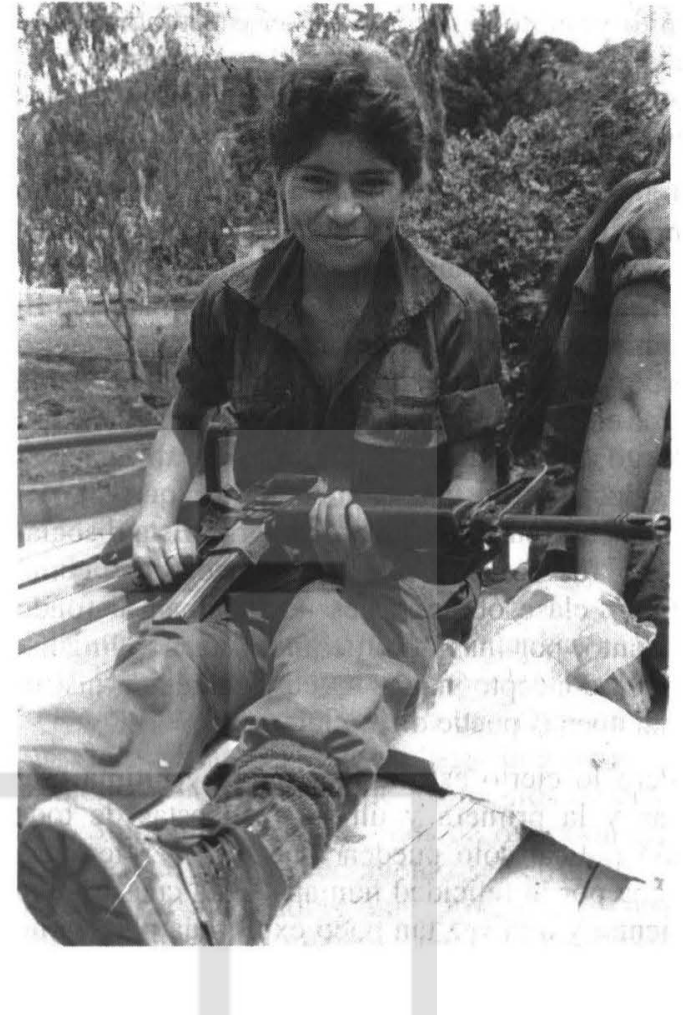

nómico y de mercado hostil- pueden ir construyendo nuevos agentes sociales con capacidad productiva para un futuro de gobierno de la izquierda.

Así, pues, consideramos necesario revisar la función de la propiedad. Y junto a ello debemos y podemos señalar aquellas líneas de transformación económica que apuntan en una buena dirección y pueden constituir aspectos del tránsito necesario hacia una sociedad alternativa. Una economía mixta que ponga el acento en la orientación social del mercado, en el adelgazamiento de la gran propiedad privada, y el crecimiento de la propiedad social en sus diferentes formas asociativas, individuales y estatales.

Pero ya decíamos que el socialismo no puede limitarse a un mejor reparto de los recursos y la riqueza. Antes que nada debe erigirse en alegato humanista, en proyecto multilateral.

\section{Vindicación del humanismo}

Las palabras revolución, patria, socialismo, liberación y comunismo, han tenido en la cultura de la izquierda un componente de abstracción, otro 
de mito y, en todo caso, una fuerte autonomía que las alejaba paradójicamente de la comprensión consecuente de su finalidad: la emancipación de los seres humanos.

La asunción de los grandes objetivos ha tenido siempre una dosis elevada de politicismo, frente al que el humanismo aparecía como una idea o sentimiento débil, más propio de opciones místicas. El humanismo como filosofía era, además, un cierto estorbo para el marxismo militante que no debía reparar en medios con tal de alcanzar los fines. Sin embargo, el idealismo, el riesgo y la abnegación, han sido parte de una cultura de la izquierda conectada con la misión revolucionaria. Esta disociación no fue resuelta por voces mediáticas como pueblo y clase obrera, pues no llegaban al fondo del asunto, por más que fueran un avance lingüístico del concepto masas - cuyo carácter instrumental apenas puede disimularse.

Pero lo cierto es que la primera y última preguntas y la primera y última respuestas de toda acción radical sólo pueden tener como referencia la lucha por la felicidad humana. Esta cuestión tan clemental y a la vez tan poco explorada plantea no pocos problemas y tortuosas dudas acerca de fines y medios, como si puede ser bueno o deseable todo cuanto pueda lograrse mediante la lucha, y todo cuanto se proponga como necesario.

Allí donde el ultrapoliticismo reinaba, la eficacia se levantaba como lo auténticamente real (correcto), de modo que cada hombre o mujer de izquierda era principalmente un medio, un instrumento disuelto en lo colectivo - lo verdaderamente importante. Esto llevó a que en el interior de muchos partidos se diera una especie de moral revolucionaria que vigilaba los comportamientos que pudieran lesionar a la disponibilidad militante.

Frente a este enfoque que se sinteliza en "la sociedad lo es todo, la revolución lo es todo, el partido lo es todo", hacen falta nuevos movimientos atentos a todas las dimensiones que conciernen a la vida humana, en sus aspectos individual y colectivo. Es la reivindicación del individuo libertario y de una nueva concepción de lo colectivo; simbiosis que requiere una revisión. Decía Martín
Buber: "El afán por lo justo no puede realizarse en el individuo, sino sólo en la comunidad humana". Pero la dimensión colectiva no puede nunca ahogar las diferentes individualidades que la componen. La individualidad autónoma, consciente, capaz de ser diferente y de elegir por sí misma a diferentes niveles y por diferentes caminos, es condición necesaria para una sociedad libre no domesticada.

El humanismo radical se rebela contra el destino fatal de lo históricamente necesario, que ha sido fuente de esquematismos y hacía de las personas meros miembros de organismos depositarios más o menos clónicos de ideales generales y normas de conducta establecidas, revolucionariamente correctas. No debe haber ninguna misión sagrada, ningún mandato redentor que gobierne nuestros actos fuera de nuestra voluntad. Somos nosotros mismos los que decidimos lo deseable, la bondad de la sociedad por la que luchamos. A tal punto, que la posibilidad de alcanzarla realmente -en nuestras vidas - se vuelve secundario frente a la importancia del impulso de luchar por ella. A este respecto podemos decir:

"Que lo que llamamos socialismo no es producto necesario, sino posible, y que nada ni nadie nos garantiza un linal feliz que, durante mucho tiempo y por virtud de una interpretación cientifista, nos prometían fatales leyes del movimiento de la historia". "Que la posibilidad del socialismo exige de la praxis humana, de lo contrario pasaría de la causalidad a la casualidad".

"Que el problema de ganar a la mayoría para semejante objetivo, sobrepasa con mucho las cuestiones de estrategia política". "Que la praxis emancipadora plantea un paso del ser al deber ser que precisa de una posición ética, ajena a toda moral petrificada en códigos". "Que esto exige de los grupos y partidos de izquierda una crítica radical a la civilización occidental que va mucho más lejos de la crítica económica; y que la propuesta alternativa es multilateral y no se centra particularmente en la cuestión de la propiedad".

Es útil señalar que la discusión sobre la posibilidad no es marxista de Marx. Pero aun cuando no 
está demostrada la inevitabilidad de la revolución, lampoco su imposibilidad. El humanismo revolucionario propone poner palas arriba algunas concepciones clásicas de la izquierda. El comunismo deja de ser el reino de la libertad y el fin de las contradicciones. Es imposible como sistema y como calegoría que pone fin a la historia, y supone que la humanidad ha vencido por fin a la naturaleza y a sí misma. Es más interesante contemplarlo como una inspiración en lavor de la mayor igualdad, de un nucvo mundo, de una justicia en constante perlección, todo lo cual conecta con los sufrimientos de los vencidos en la versión del gran Walter Benjamin.

Del mismo modo, el humanismo revolucionario propone acercarse al fenómeno religioso para ver en él una obra humana. No hay respuesta teórica al hecho religioso. El desarrollo de las fuerzas productivas no puede poner fin a las alienaciones religiosas. El dolor, la soledad, la vejez y la muerte, no son simples episodios; son inherentes a la condición humana y móviles espirituales. La pretensión del marxismo vulgar de acabar con la religión, no es sino una demosiración de economicismo y de lálta de investigación de las ideologías populares. $Y$, sin embargo, también podemos añadir que: el ser humano no es de ninguna manera, es en su proceso de vida real, lo que quiere decir que puede afrontar el hecho religioso de manera cambiante y puede emanciparse desde él o sin él.

Ligar marxismo con ateísmo es una aspiración absurda con pretensiones salvíficas. El humanismo revolucionario propone un nuevo lugar para la moral. Esta no es un subproducto de la lucha de clases y del movimiento de la historia. El socialismo como meta liene mucho más que ver con la moral que con la ciencia, en realidad la ciencia no tiene nada que decir pues se mueve en otro ámbito. La idea de que la moral debe acompañar al mandato histórico de las contradicciones en el capitalismo cra propia de quienes creían que el desenlace de la revolución se jugaba principalmente en el campo de lo económico. Pero no hay una ley por encima de la voluntad humana, por más que ésta se vincule a la rcalidad exterior en que vive. "El hombre es la raíz del hombre", como magníficamente decía el joven Marx.

El humanismo expresado como crítica y construcción sólo puede desarrollarse desde la radicalidad e inflexibilidad frente a toda opresión. Es una tensión permanente en favor de la igual- dad, de la libertad, del feminismo, de la ecología... En el núcleo humanista late el deseo de felicidad; loda la lucha revolucionaria busca el fin de la infelicidad en la esfera de lo posible.

Esta visión amplia significa un pensamiento y una acción que afronten críticamente el Estado y las prácticas políticas predominantes en occidente, la dualización de la sociedad y la explotación, las relaciones entre las personas y entre los sexos, el insensato uso de los recursos nalurales, la gran ciudad actual -como síntesis superior de la civilización occidental-, el trabajo, el empleo del tiempo y el ocio, el sistema mundial y la división nortesur, los medios de comunicación, la humillación de algunos grupos étnicos...

Humanizar la sociedad deshumanizada, humanizar la política, humanizar la violencia obligada de los oprimidos. Esto invita a una revisión de los conceptos clásicos anticapitalistas que reducían el problema a la propiedad de los medios de producción. Son numerosos los hilos de reflexión que se pueden escoger: el crecimiento selectivo, la decisión democrática sobre qué producir, el trabajo como satisfacción, nuevas pautas del consumo, la democracia genuina de los consumidores, una educación orientada al conocimiento y a la espiritualidad, el ingreso anual garantizado, el fin del militarismo, el rescate democrático de la política, la sociedad participante, la sustitución de la burocracia por una administración humanista, la tendencia a la igualdad universal...

La praxis humana exige la utopía, no contemplada como diseño de la sociedad futura (resulta difícil pensar una sociedad física), ni como perfección, ni como armonía, ni como verdad universalizable (siguiendo la crítica de Isaiah Berlin), sino como rechazo de lo existente, imaginación, sueño humano e impulso. No pensamos en una utopía normativizadora, sino que pensamos en ella como tensión humana, como deseo de ruptura. Pero, además, ¿no puede decirse que una meta utópica es más realista que el "realismo" de los ideólogos neoliberales?

En cierto modo la izquierda tiene un destino utópico. Pero no porque confiemos necesariamente en el futuro, ni en las virtudes de la especie humana, sino porque la utopía como inconformidad con lo que existe y como esperanza de lo nuevo es la conveniencia de creer en algo mejor; lo nuestro es la incertidumbre. Nuestra sustancia moral, nuestro 
sentido subversivo, nuestro romanticismo radical, no son sentimientos ajenos a la utopía. O dicho de otro modo, no hacemos lo que hacemos sólo por quedar bien con nosotros mismos; lo hacemos asimismo porque aspiramos a un cambio profundo.

La actual civilización occidental y el progreso, bajo la hegemonía del neoliberalismo, extienden el individualismo alienante y la soledad (vivimos una gran soledad en compañía), la angustia, el afán de acumulación, la insatisfacción espiritual, la frustración profesional, las relaciones contaminadas por el interés particular, etc. El humanismo revolucionario es la rebelión a esta civilización, no porque sepa que puede triunfar sino porque es la causa de los vencidos de hoy.

Finalmente, el humanismo como universalidad de valores, como moral de morales; reconocimiento de la humanidad ajena desde la humanidad propia. Universalidad que no quiere decir homogeneidad frente al pluralismo - una cultura frente a muchas culturas-, sino que es el denominador común de cuanto significa derechos humanos, igualdad, justicia, libertad... Hay un derecho moral a la diferencia, pero no una diferencia de derechos morales, nos dice el filósofo Fernando Savater; lo que consiste en la aspiración de extender la solidaridad, de proteger determinados derechos. Concebir el mundo como el lugar de una suerte común del género humano, e indignarse por las injusticias de todas partes; vivir el destino de lo más lejano con la intensidad de lo cercano. Universalismo como nueva cultura civilizatoria en diálogo permanente, el bosquejo fundacional de una nueva realidad humana.

Pero parece de interés insistir un poco más en la cuestión moral, ahora en relación con el marxismo.

\section{La moral y el marxismo}

Resulta paradójico que el socialismo no científico creara las ideas en las que posteriormente se asentaría el socialismo cientílico. Lo cierto es que la separación entre concepción materialista y ética fue un itinerario que recorrió el propio Marx, aunque durante toda su vida estuviera inspirado en una fuerza moral (El Manifiesto Comunista es un himno a la pasión). En su empeño por superar el mundo idealista de Hegel que ponía en el centro del Universo a la Idea, y que hace descender al cielo sobre la tierra, Marx puso en el lugar principal a las bases materiales, ascendiendo de la tierra al cielo: "El modo de producción de la vida material determina el proceso social, político e intelectual de la vida en general. No es la conciencia de los hombres lo que determina su ser, sino, por el contrario, es su existencia social la que determina su conciencia".

Este modo de relacionar la base material con la superestructura proporciona a su vez el marco para otra conocida afirmación: "Las ideas dominantes en una sociedad se corresponden con el modo de producción dominante". No faltan quienes señalan una contradicción entre las dos tesis que acabamos de señalar: mientras la primera, el ser social determina la conciencia, incita a pensar que la situación de la clase obrera propicia una conciencia de resistencia contra la explotación; la segunda, la ideología dominante que es la de la clase dominante, sugiere lo contrario: la sumisión a las ideas burguesas dominantes. En todo caso nos interesa insistir en la idea de que la extensión y el triunfo del marxismo científico produjeron un corte demasiado grande entre lo político y lo espiritual.

No considerar la ética en la fundamentación de los objetivos revolucionarios hizo que Marx y Engels no prestaran atención al problema de los medios empleados en la lucha: "Son buenos todos los medios empleados para lograr un buen fin, es la pauta utilitarista más extendida en el marxismo". Engels señaló: "Todo medio me parece bueno, el más violento y el más suave, para alcanzar el fin".

La teoría de la revolución de índole marxista coloca la moral en un lugar derivado, subproducto de la actividad política. ¿Por qué? Porque el fundamento ético no asegura el socialismo, y la concepción materialista apoyada en el desarrollo de las fuerzas produclivas, sí. La diferencia cs notable. Hay marxistas que han escrito sobre los valores éticos; pero presentan el deber ser como deducido de la necesidad: la valoración moral basada en el fundamento del conocimiento de leyes históricas.

Son bastantes los marxistas que han luchado por hacer de los dos fundamentos, el científico y el moral, ámbitos que se necesitan mutuamente, pues ninguna de las dos fundamentaciones por sí sola es suficiente (Vorlaender, Woltman, Bauer, Tugan-Baranowski, Adler...) Los de la escuela de Frankfurt irían más lejos y pondrían el acento en su crítica al desarrollo como motor de las contra- 
dicciones, invocando sobre todo a la conciencia. Sin embargo, más allá de autores y grupos de pensamiento que tuvieron influencias limitadas, el marxismo triunfante se preocupó poco o nada de la cuestión moral. Una corriente humanista más tarde fundó la socialdemocracia que hoy configura la Internacional Socialista. Gabriel Deville centra bien el planteamiento del marxismo más extendido cuando escribe:

"Cualquiera que sea el valor subjetivo de la moral, del progreso y de otros grandes principios, esta hermosa fraseología no influye para nada en las fluctuaciones de las sociedades humanas; por sí misma es impotente para lograr el menor cambio. Las evoluciones sociales las determinan otras consideraciones menos sentimentales. Sus causas se encuentran en la estructura económica, en el modo de producción y de cambio que preside la distribución de las riquezas y, por consiguiente, la formación de las clases y su jerarquía. Cuando estas evoluciones se efectúan no es porque obedezcan a un ideal elevado de justicia, sino porque se ajustan al orden económico del momento".

La moral se refiere a los valores que deben inspirar el comportamiento y la naturaleza de los objetivos. Por ejemplo, el socialismo como meta tiene mucho más que ver con la moral que con la ciencia; en realidad, la ciencia no tiene nada que decir puesto que se mueve en otro ámbito. Eugenio del Río asegura que la fórmula misma <<socialismo científico $\gg>$ refleja la confusión entre las proposiciones cicntíficas y las proposiciones normativas, las referidas a las conductas que se consideran valiosas desde el punto de vista ético.

Para Eugenio del Río, en Karl Marx podemos ver lo siguiente: "Un Marx explícito más bien amoral; otro Marx, a veces explícito, pero generalmente implícito bastante moral". Hay una contradicción entre su "amoralismo científico" y el impulso moral latente en su obra. Las corrientes marxistas posteriores han armado bastante lío con esta herencia. La mayor parte de las veces se ha puesto cl acento en la crítica de la moral abstracta y se ha desconsiderado la cuestión moral.

En las organizaciones de izquierdas siempre hay una verticnte moral implícita. La lucha tiene siempre un impulso que va más allá de la satisfacción de saber que se camina, supuestamente, a favor de la historia. Otra cosa es en qué medida se asumen como tales los valores morales. El ámbito de estos valores no ha tenido un lugar importante en los estudios y las discusiones en las fuerzas revolucionarias. No es arriesgado decir que aquellas militancias que confesaban espiritualidad y móviles humanistas, eran vistas como signos de debilidad por buena parte del resto. Todavía el hecho religioso es tratado con prejuicios en algunos partidos revolucionarios; hay militantes que ocultan sus creencias, y militantes que combaten a los creyentes desde un ateísmo marxista.

La cuestión moral debe ser considerada con mayor atención. Ahora bien, ¿hace falta un código moral? ¿Es conveniente que sea marxista? Un código moral son los diez mandamientos. Un enunciado de preceptos y criterios para distinguir el bien y el mal. Algo así no parece necesario. Tiene inconvenientes, ya que las definiciones precisas y formales alimentan una comprensión formalista y unas discusiones formalistas para ver si tal o cual comportamiento se ajusta al código.

Más interesante parece esbozar, de maneral general y no codificada, ciertos valores que deben inspirar la acción revolucionaria (solidaridad, fra-

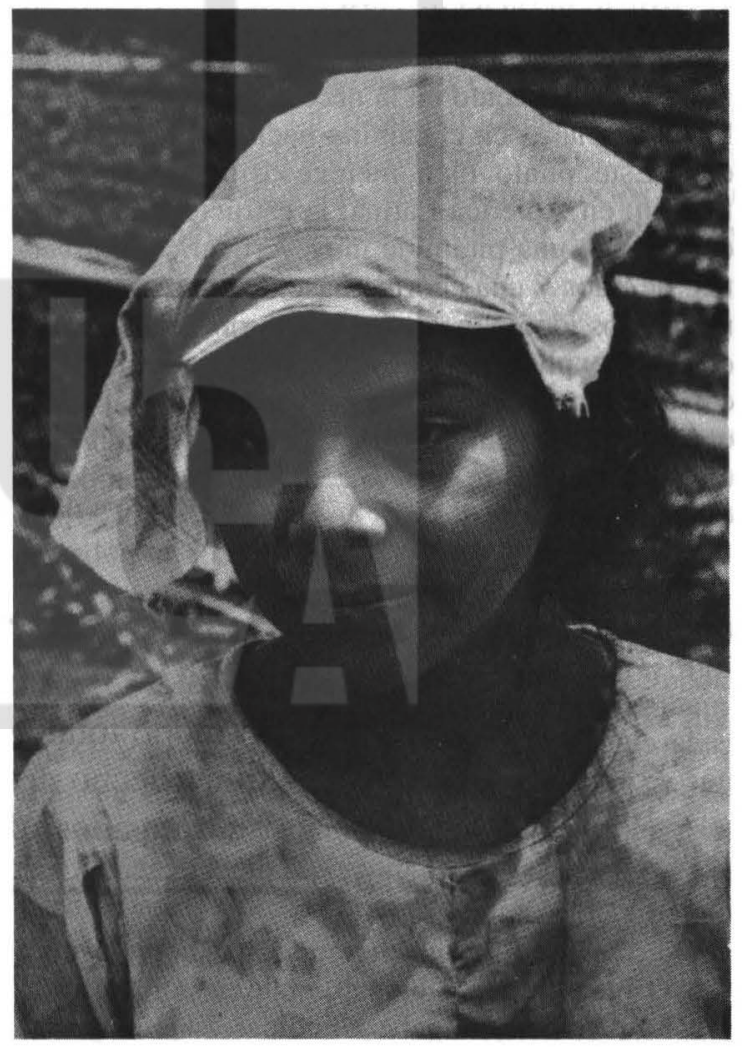


ternidad, igualdad, abnegación, indignación frente a la injusticia, odio al racismo y al machismo...)

¿Una moral marxista? No tiene sentido enfocar la cuestión en términos de exclusividad marxista. Posce cierto interés reconstruir los valores morales latentes en la obra de Marx. Pero al hacerlo veríamos que no hay en ellos una especifidad, veríamos que no son distintos los valores morales de Marx, Fourier, Sorcl, Bakunin... Los mejores valores morales de los marxistas de hoy son en buena medida parecidos a los mejores valores morales de los anarquistas, de los sectores cristianos socialistas, e incluso de liberales al estilo de Stuart Mill. En la esfera de la moral revolucionaria no es posible trazar fronteras precisas. Hay un terreno de encuentro entre personas revolucionarias de distintos orígenes, ese terreno es el humanismo.

El humanismo radical se lunda precisamente en el amor y el odio. En el amor a la justicia y la libertad, y en el odio a toda explotación y opresión del género que sea. Humanismo y lucha de clases no se oponen, con frecuencia se necesitan.

\section{7. ¿Murió la lucha de clases?}

Es frecuente escuchar voces desde la izquierda que ponen el acento en la necesidad de desterrar la lucha de clases en el camino hacia la nueva sociedad. Este punto bien merece asimismo una rellexión: en América Latina, la estructura de clases comprende una pirámide muy vertical con un vérlice de ricos y una enorme base de pobres. Lógicamente, los ideólogos de las clases dominantes acuden a la explicación del funcionalismo para explicar que las clases sociales no responden al lugar que ocupan en las relaciones de producción sino que son reflejo de una relación de oportunidades en el mercado: los listos y emprendedores triunlan, los tontos y perezosos se merecen la pobreza. A cllo le añaden unas golas de predestinación religiosa y pintan así un cuadro social en el que cada cual ocupa el lugar que se merece".

Es evidente que la lucha de clases constituye un concepto actual, vigente, no una presunta herencia del dogmatismo. Cosa distinta es si la lucha de clases se manifiesta mucho o poco, y si cabe adjudicar a las mayorías pobres unos idénticos intereses objetivos y subjetivos.

La lucha de clases no es una idea arbitraria inventada por la izquierda. Basta observar la composición de la propiedad en los países latinoamericanos, y basta con conocer la tradicional posición excluyente de las oligarquías para concluir que muchas de las rebeliones, huelgas y protestas de buena o gran parte de los pueblos a lo largo de la historia tenían y tienen un componente substancial de lucha de clases.

Sin embargo, es cicrto que con frecuencia hemos reducido la visión de la sociedad a la lucha de clases. Hemos reducido esta lucha a la existencia de dos clases: burguesía y proletariado (la palabra proletariado la hemos considerado sinónima de Irabajadores de toda índole, sectores informales, marginados, clc., las grandes mayorías que son los pobres). Y es cierto que a la hora de definir la confrontación entre ellas, hemos dicho que el resto de los sectores sociales sólo pucden elegir si aliarse con una o con la otra. Esta forma de ver a la lucha de clases como el motor de la historia nos ha llevado a concentrar nuestra acción y pensamiento en el objetivo de agudizar esta contradicción, viendo en ello el desenlace de la revolución.

Esta mancra de accrcarnos a la realidad ha tenido varios inconvenientes: nos llevó a creer que la lucha de clases es el único molor de la historia, no considerando otro buen número de contradicciones, esto es, las luchas democráticas, las luchas indígenas, las luchas de liberación nacional y antiimperialista, la opresión de la mujer, los enfrentamientos culturales, la crisis ecológica... Nos condujo también a la idea reduccionista de creer que las mayorías pobres tienen unos mismos y uniformes intereses de clase, de los cuales la izquierda somos los portadores. Adjudicarle unos intereses a una mayoría que no los asume como tales, ha sido un error habitual de la izquierda. Lo cierto es que la condición económica, de pobreza, no es suficiente para decidir qué intereses tiene el pueblo, al margen de su conciencia y de sus preferencias políticas que muchas veces se revelan distantes de la izquicrda. Es así que no somos portadores de unos intcreses de las mayorías. También 
nos llevó a no considerar correctamente a sectores sociales nacionales que están a favor de la democratización del Estado.

En el futuro, buena parte de las movilizaciones por la tierra, o por una vivienda digna, o por el empleo, etc., tendrán un componente de lucha de clases. Es más, una hipótesis de gran confrontación social no puede concebirse al margen del fenómeno de lucha de clases. Sin embargo, la democratización del Estado no podría continuar si no es unicndo a toda la parte de la sociedad que está de acuerdo en ello. La lucha contra la extrema pobreza, etc., nos plantea la necesidad de apoyarnos en todas las fuerzas sociales y políticas que comparten los mismos objetivos. Mónica Baltodano nos recuerda que: "la labor de la izquierda es promover la lucha de clases sin desestimar la emergencia en el terreno de la vida, en unión con los nuevos sectores sociales, grupos e individuos, sin despreciar nada, dando lugar a todas las expresiones de la conciencia posible y sus manifestaciones a cada inslante de nuestro transcurrir. Afirmándonos y revelándonos, tejiendo los vínculos sin prejuicio, promoviendo la fraternidad, la audacia, la cooperación, la solidaridad".

De la misma mancra que antes adjudicábamos, erróneamente, a las clases populares intereses de los cuales no tenían conciencia, malo sería adjudicar ahora a las clases ricas intereses nacionales de lo cuales no tienen conciencia o simplemente se manifiestan en contra. Por ello, la democratización del Estado no es algo ajeno a intereses de clase y sectores sociales diversos.

En otro ámbito de reflexión, la continuidad y profundización en las cuestiones de género y ecología, campos a los que cabe añadir el fenómeno de la juventud que requiere de una política específica, exigen un trabajo abierto que no se agota en la lucha de clases. Numerosas contradicciones en estos ámbitos, como en los de la política y la cultura, no se explican bien desde la lucha de clases.

Así, pues, no se trata de pasar de un enfoque a otro de un modo total. Si antes analizábamos cualquier hecho desde la lucha de clases, no se trata ahora de hacerlo al negarla. La cuestión consiste en acercarse a cada problema sin un esquema previo; conocerlo y acluar de acuerdo a cómo se manifiesta realmente.

También merece atención el concepto de nación por el lugar importante que ocupa en la iz- quierda. En el camino hacia una sociedad alternativa, la construcción de la nación tiene un papel ciertamente decisivo. Pero conviene tener presente los criterios siguientes.

El Proyecto de nación no es una abstracción, una consigna carente de una opción por los pobres. El Proyecto de nación no es una forma de disfraz de lá izquierda para concertar acuerdos con la derecha, es un proyecto que descansa en la aspiración de hacer un Estado y una democracia al servicio de las mayorías. El Proyecto Popular no es una concepción sectaria de la Nación, una forma de concebir a ésta última como propiedad de los pobres.

Ambos proyectos se fusionan en las ideas de luchar por máxima democracia, máxima libertad, máxima igualdad, máxima solidaridad, sin que podamos decir de antemano cuánto de cada una de éstas propuestas vamos a lograr. Lo lógico es que el Proyecto Popular sea más avanzado que el Proyecto de nación. Este último estará vinculado a políticas de alianzas y concertaciones mediatizadas por coyunturas y correlaciones de fuerzas. Sin embargo, el Proyecto Popular -que contempla la democracia participativa y la rcivindicativa, las experiencias autogestionarias, las economías populares - se revelará un paso por delante, como el paradigma de Nación que queremos construir. Pero aún así, no debemos separar ambos proyectos como cosas distintas, sino saberlos ver como algo concatenado, que se interrelaciona.

\section{Etica y política}

Si humanismo y moral son ingredientes de una nueva idea de socialismo, el problema de la acción política de la izquierda parece, con frecuencia, una prueba de fuego difícil de superar.

Sin embargo, el debate acerca del papel de la ética en el ámbito de la política interesa cada vez más a la izquierda. A ello contribuye la conciencia de la necesidad de explorar alternativas a ese mal endémico que atiende al nombre de corrupción y más, en general, al deseo de superar los límites de una democracia parlamentaria atrapada en las viejas mañas del clientelismo, de la demagogia y la partitocracia.

La vida democrática, entendida como participación ciudadana, se distancia cada vez más de la democracia realmente existente cuyos rasgos más 
acentuados son, tal y como indica Eugenio del Río en su Crítica a la política en Occidente: (1) Conformación de un campo político formalmente independiente de las clases sociales y funcionalmente autónomo. (2) Existencia de un cuerpo social (burocracia estatal permanente, especialistas y técnicos, políticos profesionales, etc) por encima del conjunto de la sociedad y con intereses propios. (3) Concentración de la actividad política en una minoría con escaso interés real por desplegar el poder en la sociedad. (4) La política como competencia es, sobre todo, una lucha entre élites con aspiraciones de gobierno. Los propios partidos eslablecen maquinarias de control de sus miembros y cargos políticos, restándoles autonomía y haciéndoles meros apéndices de su organización. (5) Incumplimiento habitual de las promesas electorales, con lo que el voto ciudadano carece de control y se hace inviable el contrato entre el votante y el votado. (6) Uso de los recursos públicos para fines partidistas, de grupos de presión e incluso para intereses particulares de los políticos.

La política concebida como servicio público, basada en una concepción altruista, parece haber perdido mucho terreno al menos a nivel general. La profesionalización y la apropiación de la democracia electoral por los partidos políticos, hace muy difícil que la gente de la calle se interese por la política y vea en los partidos instituciones en las que confiar. No es entonces extraño que los políticos sean para los ciudadanos personas sospechosas.

La ética se propone regenerar la vida institucional, la acción de gobierno, y a los propios partidos políticos. Pero el debate mismo sobre esa posibilidad no es sencillo si nos atenemos a los hechos.

Son dos los enfoques principales que predominan: uno de ellos reivindica la ética basada en las convicciones de conciencia; el otro defiende la ética política basada en los resultados, en lo que se denomina el consecuencialismo. Se trata, en realidad, de dos proposiciones que han luchado entre sí a lo largo de la historia de las ideas políticas a partir de la antigua Grecia. Sin embargo, a partir de Maquiavelo, a principios del siglo XVI, es cuando se da la ruptura definitiva del peso de la moral en la acción política, bajo el argumento de que la conquista y el mantenimiento del poder no pueden hipolecarse a consideraciones que pertenecen a otro ámbito. El éxito de Maquiavelo llega hasta nuestros días $y$, sin embargo, no por ello ha dejado de ser contestado por los herederos de Kant que estiman necesarios valores morales absolutos, de Rousseau, de liberales como Stuart Mill, del marxismo del joven Marx y del socialismo humanista. Sea como fuere, en el debate actual, las posiciones extremas tienden a equivocarse. Es necesario un equilibrio que debe madurar con la experiencia y que no tiene porqué ser simétrico.

La ética basada en convicciones de conciencia tiene la ventaja de atenerse a principios sólidos, fuertes. La justicia, la igualdad, la solidaridad, etc. se proponen como el cimiento permanente e invariable de toda política. Al no ser valores sujetos a las turbulencias de las coyunturas, ni a tácticas electorales, constituyen los pilares de un programa regeneracionista en el que pueden confiar los sectores sociales más desfavorecidos, así como los partidarios de una nueva democracia. La desventaja de esta ética es que choca con la realidad, porque ésta última propone la tiranía de ser sobre todo eficaces más que morales. La realidad y su correlación de fuerzas empuja a la izquierda a actuar de manera gradualista, haciendo acuerdos con fuerzas políticas y sociales que difunden y defienden valores opuestos. Una ética basada en convicciones de conciencia que no tienda a ser flexible puede terminar inspirando conductas autoritarias, funcionando como una estructura de ideas religiosas ajena al curso de la vida real.

Por su parte, la ética política basada en los resultados tiende a adaptarse mucho más a la realidad del mundo. Por ello tiene infinitamente menos prejuicios para transgredir principios, ya que su vocación es la eficacia y, por ende, fija su atención en las consecuencias. No cabe duda que esta ética es la triunfadora a finales del siglo XX, pues guía la actuación de gobiernos y partidos mayoritarios en todo el mundo. A diferencia de la ética anterior, es antropológicamente pesimista y cree por consiguiente que la mecánica de la política no debe tener la ambición de una nueva sociedad de seres éticos, sino simplemente proporcionar una convivencia en las mejores condiciones posibles. Pero la gran desventaja de la ética de los resultados es que para ella el fin justifica los medios, haciendo del pragmatismo una nueva doctrina de inclinación absoluta.

Así, por ejemplo, donde la ética de conciencia condene siempre la pena de muerte por ser intrínsecamente mala, la ética de los resultados puede aceptarla si la sociedad la exige y los réditos elec- 
torales son buenos (es el caso de Estados Unidos). Así, por ejemplo, donde la ética de conciencia combata siempre la corrupción en el Estado, y aunque se trate de asuntos del pasado pida justicia, la ética de los resultados puede preferir el punto y final en aras a concertar un nuevo escenario con nuevas reglas del juego. Pero no todos los ejemplos son de este signo. Hay ejemplos que justifican la virlud de la ética de los resultados cuando la ética de conciencia defiende el todo o nada. La concertación social y los acuerdos con la derecha en asuntos de Estado, defensa o política exterior, pueden servir en ocasiones mejor a los intereses de las mayorías que las posiciones puritanas reivindicativas.

El debate liene en la izquierda a seguidores de una y otra ética. Unos tienden a preservar lo que consideran más sustantivo: ese conjunto de valores decisivos para un mundo mejor; los otros defienden la necesidad de lograr resultados en un mundo político hostil en el que la derecha juega con la ventaja de no tener escrúpulos morales. Ahora bien, ¿por qué oponer de manera radical y excluyente lo bueno de uno y otro pensamiento? La relación entre ambas éticas dehería escoger sus partes positivas, no para confundirlas sino para apoyarse mutuamente. De modo que si la ética de conciencia debe actuar como vigilante de la ética de los resultados, ésta última debe exigir a la primera poner los pies en el suelo. No se trata en todo caso de armonía sino de apoyarse conflictivamente.

Decía con anterioridad que no se trata de un equilibrio simétrico. Ciertamente es cuestión de proporciones, digamos que un 60 por ciento de élica de conciencia y un 40 por ciento de ética de resultados. ¿Por qué así y no al revés? La respuesta tiene que ver con los liempos en que vivimos. Y, en efecto, la lucha por el poder en nuestras sociedades ata a la izquierda a las encuestas y sobre todo a los resultados de las urnas. Ganar la mayoría de votos supone mirar hacia el centro, moderar el discurso, llegar a acuerdos con los empresarios, contener todo radicalismo, considerar la política internacional adversa, etc. $Y$ todo esto quiere decir que el pragmatismo encuentra en la vida misma suficiente presión y llamadas al orden. La ética de los resultados se encuentra como pez en el agua, en tanto que la ética de conciencia vive a contracorriente, empujada hacia la marginalidad. Hace falta, pues, primar a la conciencia puesto que la otra ética ya cuenta con suficientes incentivos.

El debate sobre la función de la ética en la política no debería, en todo caso, concluir precipitadamente. Al contrario, conviene mantener la tensión y el descontento, considerar que siempre es y será un tema de actualidad necesitado de nuevas ideas y mejores equilibrios. Para ello, nada mejor que la izquierda huya de toda complacencia y se convierta en la mejor crílica de sí misma.

A propósito de ética, conviene asimismo reflexionar sobre aquella que debiera desplegarse en el interior de la propia izquierda. No vaya a ocurrir que la palabra ética se asocie únicamente con la acción pública, olvidando que una izquierda que se proponga como alternativa social y política debe manifestar hacia adentro de sus propias filas algunos valores que la hagan creible.

\section{Del colectivismo a la solidaridad}

La solidaridad, la ayuda mutua, lo asociativo, la acción colectiva, la comunidad de bienes, son valores propios de la izquierda (la derecha ha predicado siempre que se trata de valores que anulan al individuo y son de signo totalitario). La izquierda ha practicado en mayor o menor medida esos valores que seguimos considerando una propuesta emancipatoria de extraordinaria importancia para el presente y el futuro.

El valor de lo colectivo ha sufrido con frecuencia un descrédito cuando la izquierda ha ejercido el colectivismo como dogma, forzando a la gente a asociarse. Hay sin duda una diferencia y no sólo de lenguaje entre la vida colectiva voluntaria y el colectivismo entendido como una estrategia económica, social y política, impuesta por la izquierda en el gobierno o fuera de él.

En el llamado socialismo real se empujó al campesinado a organizarse colectivamente para acceder a la tierra. En los primeros años de la revolución sandinista se primó el colectivismo en el campo mediante la concesión de tierras y créditos a las cooperativas, estableciendo muchas dificultades para quienes aspiraban a ambas cosas de manera individual. A mediados de la década de los ochenta, los sandinistas rectificaron pues se dieron cuenta que el colectivismo impuesto se volvía en contra de la revolución.

Pero si el colectivismo forzoso hace un flaco favor a lo comunitario, en el otro lado el neoliberalismo ataca también a lo colectivo tachándolo de totalitario y trata de destruir todo asociacionismo 
popular y las redes de solidaridad. De modo que ambas cosas son igualmente negativas.

Durante la guerra en El Salvador y Guatemala, la izquierda practicó junto con valores asociativos positivos otros, que si bien fueron tal vez necesarios hoy constituyen un lastre: la dependencia de una estructura jerárquica; el tutelaje del partido y de los mandos sobre el conjunto de combatientes. Las guerrillas desarrollaron una forma de colectivismo forzado por la guerra y por su inclinación a concentrar las decisiones en pocas personas por resultar más eficaz. Años de guerra han generado una cultura en la que lo individual, la iniciativa propia, la responsabilidad de cada militante, no se han desarrollado como debieran.

Hoy se plantea la necesidad de combinar equilibradamente los valores comunitarios y la individualidad en todos los planos de la vida. La solidaridad como valor para una nueva cultura, para una nueva sociedad $y$, al mismo tiempo, la responsabilidad de cada militante de la izquierda de asumir su vida privada y pública. Combinar la responsabilidad de cada cual en la vida partidaria, sin diluir responsabilidades $y$, a la vez, seguir cuidando la vida de conjunto, la reflexión socializada, la acción común y el apoyo mutuo.

Así, pues, es bueno luchar contra la idea de papá-partido del que hay que esperar respuestas y soluciones a cuestiones que atañen a la iniciativa de cada cual. No se trata desde luego de alimentar el individualismo, sino el crecimiento de lo individual, que son cosas distintas. Lo colectivo crece a su vez y se enriquece en la medida en que cada persona desarrolla sus propias capacidades, su derecho a equivocarse.

Pero reivindicar la individualidad, tan descuidada en la historia de la izquierda, no quiere decir que "cada cual se las arregle como pueda" o el "hago lo que me da la gana". Luchar contra la tentación que puedan tener algunas gentes de vivir subsidiados y bajo la protección partidaria, no debe suponer abandonar la responsabilidad que los partidos de izquierda tienen contraída con tanta gente que lo ha dado todo por la lucha revolucionaria.

Por consiguiente, la cuestión es ir ganando conciencia acerca de las responsabilidades personales y al mismo tiempo acompañar a la gente que la pasa peor, que más necesidades liene, y apoyarla en su deseo de mejorar sus condiciones de vida. Se trata de una tarea que requiere tiempo y un enfoque muy humanista del problema, huyendo de esquematismos. Hay que ser conscientes de que en el interior de las izquierdas quienes más fácilmente pueden comprender la necesidad de romper con tutelas y subsidios partidarios son las personas que tienen más recursos; pero ésta no es la situación de la mayoría de militantes.

La relación entre lo colectivo y lo individual plantea también, de fondo, el asunto de vida pública y vida privada. Ciertamente, la fiscalización, el control de la vida privada, no sólo lesiona gravemente el derecho de las personas a vivir según su conciencia; además, constituye una visión errónea de la sociedad que queremos. A fin de cuentas, luchamos por la felicidad de la gente y esto es algo inherente a la más amplia libertad de las personas. Pero esto debe conjugarse con otro criterio igualmente básico: la vida privada no debe constiluir el espacio para una doble vida, para una doble moral, para el engaño. Si la vida privada es la negación de lo que se defiende en público; si uno defiende los derechos de las mujeres en sus discursos y en casa es un señor feudal; si uno dice luchar por una sociedad mejor, más humana, más igualitaria y practica el egoísmo económico en su vida privada, la insolidaridad, elc; si hay en fin una doble moral, el problema ya no es de colisión entre vida pública y privada, perfectamente compatibles, sino de corrupción personal.

Todo esto es importante contemplar cuando se discute la cuestión de lo colectivo y la individualidad, valores ambos muy necesarios que se oponen al colectivismo dogmático y al individualismo insolidario.

\section{La democracia como dogma}

El socialismo sólo puede ser democrático para ser verdadero. Es verdad que hay un socialismo de derechas y que, en consecuencia, no puede creerse que todo socialismo es necesariamente libertario y democrático. Hay, pues, una lucha invitable desde todo socialismo por hacerse democrático para ser emancipador y no un mero sistema estatista en manos de una élite. Esta relación nos lleva a la necesidad de reflexionar siquiera brevemente sobre la democracia.

La democracia es un dogma de nuestro tiempo. Los dogmas tienen la gran virtud de permanecer en la oscuridad de las palabras. Las palabras, con 
lrecuencia, ocultan los verdaderos pensamientos, tal y como denunciaba Voltaire. Los dogmas son de gran utilidad, pues no necesitan explicación y difícilmente se pueden refutar.

El gran asunto es que la democracia como dogma es la que el politólogo español Fernández Buey denomina democracia-madre y que se corresponde con la concepción europeo-norleamericana de democracia. La democracia-madre se considera a sí misma como la única verdadera, contradiciendo gravemente a Aristóteles, quien acertadamente sentenció que hay muchas formas de democracia y no solamente una. Ciertamente pueblos muy distintos pueden adoptar formas distintas de gobicrno democrático.

La democracia-madre, según Fernández Buey, ha decidido que las condiciones democráticas son dos: una real y otra simulada. La condición real es la que asegura el libre mercado, la libertad de comercio y la menor intervención posible del Estado. La condición simulada es menos importante $y$ se reliere a la existencia formal de un parlamento y de partidos políticos. La primera condición es imprenscindible; la segunda condición es negociable y soporta perfectamente los fraudes electorales y la combinación de parlamento y represión.

Para la tradición liberal, estas dos condiciones son sulicientes, pues aboga por una democracia elitista que no requiere de la participación popular. Es así que la democracia realmente existente en América Latina sirve bien a los intereses cconómicos y deseos políticos de una minoría que no necesita de más democracia. El problema del délicit democrático es para las mayorías.

Por cierto que, generalmente, se confunden democracia y libertades liberales. Estas últimas son las libertades individuales y colectivas que por sí mismas no garantizan el demos que es el gobierno del pucblo por el pucblo. El liberalismo reconoce los derechos y deberes de un individuo abstracto, pero desarraigado de la comunidad. Por el contrario, el sentido gricgo de democracia plantea la participación significativa de los ciudadanos en la vida pública, puesto que los intereses individuales y de la comunidad tienden a coincidir. Para el liberalismo clásico, el individualismo es la bóveda del edi-

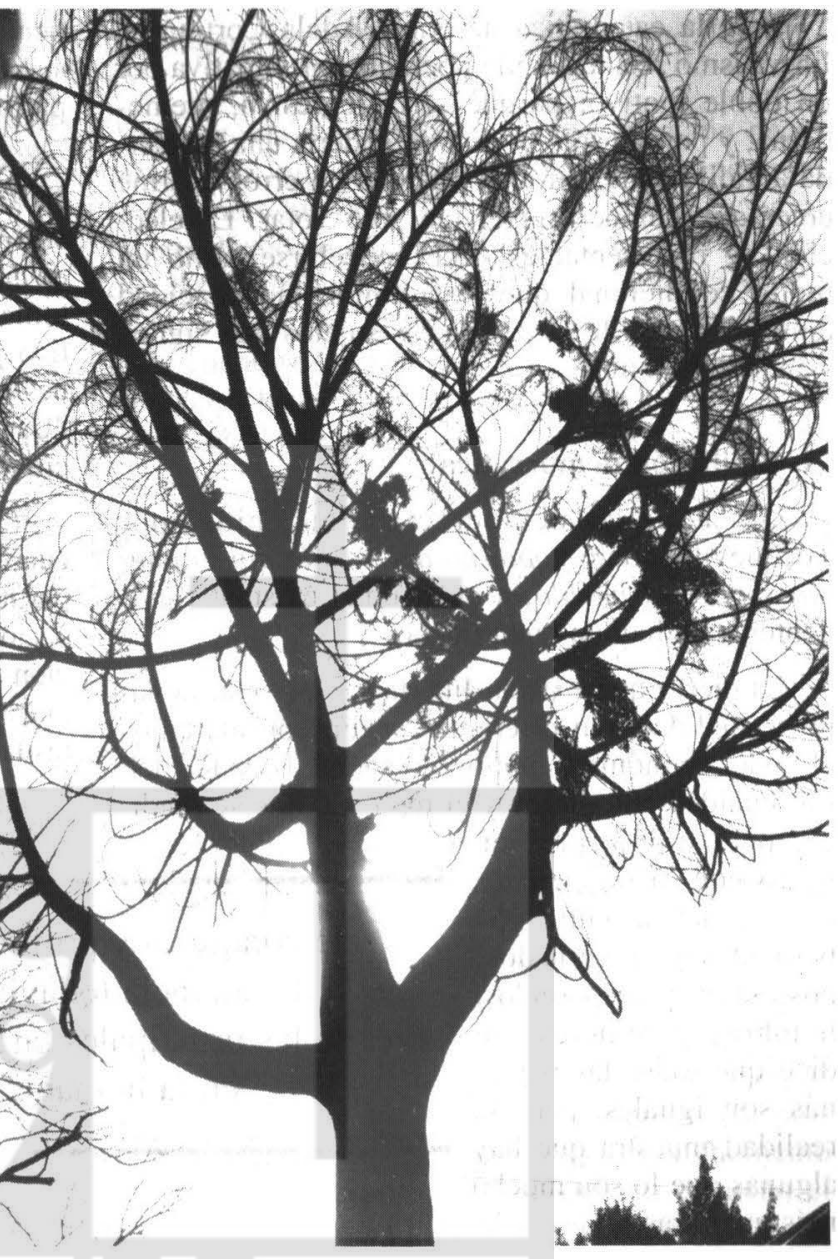

ficio político; un individuo que delega en una élite la gestión de los intereses generales.

La clave de la concepción democrática del liberalismo es que concibe al hombre como un animal económico que se sirve de la política como un instrumento al servicio de sus intereses privados. Es así que el sistema representativo predominante en la democracia-madre es un contrato de intereses privados. En esta línea se deben de cumplir las tres condiciones de las que habla J. A. Schumpeter: (1) mantener la desigualdad política entre expertos y masa como un momento estabilizador de la democracia liberal; (2) limitar la esfera política, de modo que sólo la designación del Gobierno se someta al principio democrático $\mathrm{y}$, por último (3) mantener la apatía política de la masa. Se trata entonces de una democracia querida por el pueblo más que el gobierno del pueblo. 
Para la catedrática de ética, Adela Cortina, el liberalismo rechaza la democracia participativa por un doble motivo: porque sería regresiva, premoderna; y porque sólo podría defenderla una izquierda antidiluviana. Sin embargo, es un error enorme creer que democracia es tan sólo votar. La elección de representantes debe concebirse como un modo condicional que no elimine la capacidad deliberativa de la gente, de los sujetos que siguen siendo autónomos.

\section{La ilusión democrática}

De aquella democracia concebida por Tocqueville como gobierno del pueblo por el pueblo y para el pueblo, a la realidad existente, evidentemente hay un buen trecho.

Es cierto que existen libertades, pero su tamaño y cualidad son diferentes según consideremos el poder económico, político o social de cada cual. La igualdad ante la ley y el mercado que se predica, poco tiene que ve: luego con la que existe, en la práctica, entre gobernantes y gobernados, poseedores y desposeídos, hombres y mujeres. Se dice que lodas las personas son iguales, pero la realidad muestra que hay algunas que lo son mucho más que otras.

En el mercado capitalista, la inmensa mayoría de la población se encuentra en una posición de ajencidad con respecto a los marcos de decisión del qué y el cómo se ha de producir. A lo más, las personas cuentan como consumidoras, no como productoras y, aún así, consumimos eligiendo entre las limitadas posibilidades que se nos ofrecen. Algo similar ocurre con la democracia que conocemos. La persona no es concebida como productora de la misma, sino como consumidora de ella a través del voto-moneda que se le da. El mercado electoral que se nos ofrece es también limitado. desigual y oligopólico y está luertemente viciado por:

(1) La exclusión de los principios democráticos de áreas, como la economía, lo militar, la Administración..., en los que la democracia está prescrita y donde impera, por el contrario, el poder de la dirección, la disciplina, la jerarquía. El juego democrático es sólo para los políticos, quienes a su vez están muy coartados por la hegemonía de la partitocracia.

(2) Se restringe el funcionamiento democrático a momentos determinados (elecciones), sin hacer de éste la norma principal de funcionamiento de la vida diaria. La opinión (voz) pública no es tomada en consideración salvo como dato estadístico por conocer o manipular. Las únicas opiniones que cuentan son las expresadas por las urnas: "Usted puede cambiar el voto en las próximas elecciones", se suele replicar al crítico.

(3) Las propias elecciones están tremendamente cuarteadas desde un punto de vista democrático: partitocracia, listas cerradas, imposibilidad de revocación, desigual acceso a los medios de comunicación,... El elector sólo tiene derecho a emitir respuestas, pero no a formular preguntas: "Las preguntas las hago yo", suele decir la policía y el poder.

(4) La democracia parlamentaria que conocemos está además bastante hueca. Su centro de gravedad se ha desplazado progresivamente del Parlamento al Ejecutivo. La administración se independiza cada vez más de la sociedad civil y su control, estableciendo por el contrario estrechas relaciones y dependencias -corruptelas incluidas-con los grandes poderes económicos de la sociedad.

(5) El peligro de una oligarquización de la democracia es real, no se trata de una alarma infundada. Se distingue en el hecho de que las élites de los grandes partidos se apropian de la vida pública, controlan el legislativo, pactan en secreto, coordinan las iniciativas con lobbies no siempre legales, limitan la acción de sus propios parlamentarios... La oligarquización se expresa asimismo en las reglamentaciones y reformas en las leyes electorales para favorecer el bipartidismo.

Frente a todo ello, la conquista y profundización de la democracia todavía constituyen una de las principales tareas pendientes en la humanidad. La creación de una sociedad mucho más igualitaria y justa tiene mucho que ver con todo ello. En esta andadura, algunos de los grandes trazos que podrían dibujar ese proyecto democrático serían: 
(1) La autogestión y autoorganización de cada instancia social debiera ser el principal principio por impulsar. La democracia representativa queda sometida así al principio de la subsidiariedad. Se trataría, pues, en primer lugar, de fortalecer y consolidar la función de la sociedad civil y su variada trama asociativa, mediante la potenciación de sus funciones.

(2) La democracia directa y la representativa no deben ser entendidas como opuestas, sino como complementarias. $\mathrm{Y}$, por supuesto, ninguna está reñida en modo alguno con el reconocimiento pleno e impulso decidido de las más amplias libertades de reunión, asociación, expresión...

(3) Desde su propio origen, en Grecia, la democracia fue algo más profundo que el mero hecho de hacer elecciones. Introducir en la misma elementos de control, rotatividad, revocación, rendición de cuentas, consultas directas..., debe ser algo esencial a la propia democracia.

(4) Esta, además, es algo más que un simple gobierno de la mayoría. Junto a ello existen otros derechos colectivos que no pueden ser vulnerados: derechos de minorías étnicas, lingüísticas, religiosas..; derechos de comunidades nacionales, locales..; derechos universales.

(5) Salvo que pensemos lo político como desgajado de lo social, la democracia debe afectar al conjunto de la vida social: laboral, enseñanza, administración. Además, su conquista no puede pensarse al margen de crear una base material, educativa, informativa, de relación entre los sexos, que permita a las personas situarse en una real situación de igualdad. Sin ello, pensar que la democracia puede desarrollarse plenamente, será una quimera.

\section{Utopía y democracia}

La utopía democrática no se refiere a una sociedad de la armonía. Por eso no es la utopía de Tomás Moro o Campanella. Entendida como totalidad armoniosa, la utopía es imposible pero además peligrosa. La vela autoritaria de una utopía cerrada tiene su origen en el propio Platón, quien llevado por el impulso de una reforma moral que uniese las virtudes públicas y privadas, ideó un Estado vertical conducido por los sabios. Más inofensivo era el aristócrata Sócrates, el bonachón que se paseaba intentando persuadir uno por uno a los ciudadanos de los beneficios de la virtud ciudadana.

La utopía democrática es una aspiración necesariamente imperfecta, pues demasiado imperfecto es el género humano. Se opone, en primer lugar, al hiperrealismo dominante en las democracias de hoy, que de modo falso y peyorativo tacha a la utopía de pura demencia. ¡Ojo! La utopía puede ser aceptable cuando se confiesa que no es de este mundo. Entonces, hasta el conservatismo se permite la licencia de ser utópico.

El hiperrealismo coloca a la utopía fuera de la historia puesto que proclama el fin de la misma. (¡Vana quimera! Ya los romanos creyeron que después de su Imperio no habría nada. Pero lo cierto es que la utopia, entendida como lo posible en el reino de este mundo, liene mucho contacto con la realidad. De hecho, realidad y utopía deben estar conectadas y ambas son imprescindibles. La izquierda no debe dejar a un lado a ninguna de las dos, si bien no debe confundirlas, pues el porvenir de la democracia depende de la tensión entre una $y$ otra.

No confundir utopía y realidad es importante. La primera es la crítica de lo existente y apunta hacia lo que es deseable. Entonces, resulta ciertamente real; al igual que la izquierda no debe hacer una política real sin elementos utópicos. La proporción de ambas en función de cada momento histórico constituye un reto al que no es ajeno el grado de conciencia y empuje emancipador.

Conviene aquí decir lo que sigue: el ideal utópico no se construye para defender literalmente que se convierta en hechos, sino para cuestionar los hechos y mostrar una dirección hacia la que hay que tender. $\mathrm{Si}$, como dice Eduardo Galeano, la utopía sirve para caminar, ello quiere decir que es ante todo una guía crítica y de orientación. Planteada así, la utopía puede no ser realizada pero sí dar suficientes satisfacciones.

Optimizar los ideales presupone buscar, experimentar cambios, grandes y pequeños, radicales y moderados, etc., de modo constante. Un proceso en movimiento de aciertos y errores que desdice que la historia esté acabada y rechaza la idea absurda de que la democracia parlamentaria, tal y como se muestra, sea la mejor de las formas de gobierno. Refutar el pensamiento único de una democracia-madre instalada en la realpolitik, tan chata y tan pobre. 
Un buen sistema político será el que permita hacer uso racional de su espíritu crílico y se abra nuevas experiencias. En la izquierda, con demasiada frecuencia, hay un acomodo a lo que existe, y se hace dejación de algo que ninguna otra fuerza política puede adoptar: la tensión utópica que todo lo remucve.

\section{El mundo en que vivimos}

Rellexionar sobre el socialismo requiere de alguna manera unas palabras acerca de su contextualización. ¿En qué mundo vivimos?, no es una interrogante poco importante. Merece la pena terminar cste escrito con una breve descripción de lo que está pasando a escala mundial, pues éste es el mundo en donde se trata de construir una nueva sociedad.

El mundo de finales de los años sesenta se podía comprender de una sola mirada. Sabíamos, o al menos creíamos saber, cómo estaba configurado. El mundo de hoy no es fácil de capturar racionalmente. En el mundo de ayer era relativamente sencillo formar parte de una ideología y de organizaciones con banderas fuertes. En el de hoy, las ideologías están en declive, no hay seguridades y las organizaciones se mueven en un terreno de búsqueda, algo huérfanas.

Hoy día es ya muy común hablar de una mundialización de la economía, de políticas globales de las grandes potencias, de la tendencia acelerada hacia una ecumenópolis. Todo esto surge como una novedad, como una ruptura con el mundo de los sesenta básicamente dividido en dos bloques. Sin embargo, la idea de un orden mundial es una constante en el pensamiento internacional. Toda la literatura sobre los proyectos de paz perpetua y de organización internacional responde a esta idea. En este siglo $\mathrm{XX}$ se han dado tres momentos en esta misma dirección: el que se produce a raíz de la Primera Guerra Mundial, es decir, la paz de Versalles y la primera Sociedad de Naciones; el que tiene lugar tras la Segunda Guerra Mundial, como consecuencia de la revolución nuclear; y la reacción que se produce en los años setenta frente a la gran crisis económica planetaria.

A nosotros nos interesa esta última etapa en la que el nuevo orden mundial ya no se centra únicamente en el problema de la paz, sino también en una concepción económica neoliberal y la difusión de una ideología y unos valores anticomunistas.
Pero antes, me parece interesante indicar los tres grandes paradigmas de las relaciones internacionales que describe Celestino del Arenal:

(1) El paradigma tradicional. Es el que ha dominado durante más de trescientos años, desde la paz de Westfalia, en 1648 , que puso fin a las guerras de religión y fortaleció a los cstados. El Estado es la forma por antonomasia de organización política y social, y de la teoría de la experiencia que nace de la constitución en el siglo XVII de un sistema europeo de estados. Este paradigma separa rígidamente la política interna de la política internacional. Los estados y los estadistas son los actores de las relaciones internacionales. Los seres humanos sólo cuentan como miembros de un Estado. Las relaciones internacionales son interestatales, esencialmente conflictivas, porque son relaciones por el poder.

(2) El paradigma de la sociedad mundial. Surge en los años sesenta alentado por el clima de distensión. Es una paradigma de la interdependencia que va a conocer un gran desarrollo en el mundo académico norteamericano, al abrir un debate entre paradigma tradicional y globalismo. Sus críticas ponen el énfasis en los procesos transnacionales y en los actores no estatales que van ocupando el centro de las relaciones internacionales. Su planteamiento puede resumirse así: "El mundo, como consecuencia del acelerado desarrollo social, económico, científico-técnico, y de las comunicaciones, está caracterizado por un creciente fenomeno de interdependencia y cooperación, y se ha transformado realmente en una sociedad mundial. Nuevas necesidades dan lugar a la aparición de valores e intereses comunes al conjunto de la sociedad mundial. El paradigma de la sociedad mundial o de la interdependencia insiste en el debilitamiento del papel de los Estados como entidad soberana y como estructura capaz de garantizar el bienestar y la seguridad de sus ciudadanos. El sistema internacional ha perdido el carácter estatocéntrico anterior. En consecuencia, ha desaparecido la tradicional distinción entre la esfera interna y la esfera internacional; el Estado ve restringido su margen de autonomía".

(3) El paradigma de la dependencia. Comparte con el paradigma de la sociedad global, frente al tradicional, la idea de que la realidad internacional es mucho más compleja que antes. Pero su visión ideológica se separa de la idea de interdependencia, y ve las relaciones internacionales en términos de 
dominación y desigualdad. Este paradigma de la izquierda radical -que ya fue expuesto por Rosa Luxemburgo- liene como características más relevantes: la consideración del mundo actual como un único sistema económico, dominado por el capitalismo transnacional. La naturaleza del sistema internacional es conflictiva y se basa en la desigualdad económica global, el intercambio desigual entre el centro y la perileria. Este paradigma de la dependencia ve como actores a las clases exploladas y a los movimientos de liberación, entre olros. Ve la realidad mundial dominada por el conllicto - el paradigma de la interdependencia se centra en el consenso- y como un juego de suma cero, en el que siempre hay un ganador y un perdedor. El paradigma de la dependencia es próximo -aunque no idéntico- al pensamiento marxista que ve las relaciones internacionales como relaciones de clase, uno de cuyos fenómenos es el imperialismo, de lo que se derivan dos hechos: el carácter Iransnacional de las clases, y la consideración del mundo no como dividido en estados, sino en clases antagónicas.

Sin embargo, estas corrientes de pensamiento no agotan las concepciones sobre las relaciones internacionales. En realidad, es más ajustado decir que hay un pluralismo paradigmático; no es exacto decir que el paradigma tradicional que pone al Eslado en el centro de las relaciones internacionales esté agolado. La sociedad mundial no ha vencido aún las resistencias de los intereses particulares de los cstados. En realidad, en ocasiones vemos un resurgir de los intereses parliculares que se oponen a estrategias internacionalcs. Lo vimos claramente con molivo de la guerra de los Balcanes, donde los intereses de Francia y Alcmania estaban enfrentados. Lo vemos continuamente en las negociaciones de la Unión Europea. Tenemos también un buen ejemplo en la crisis que está atravesando la ONU en los últimos años. Varios de sus organismos como la UNESCO o la FAO están siendo atacados por Eslados Unidos; la propia ONU sufre la presión de Estados Unidos por limpiarla de "tercermundismo", y el Consejo de Seguridad es un espejo de relaciones desiguales de dominación.

Por lo demás, Ignacio Ramonet señala bien como en paralelo al fenómeno de la globalización se dan fenómenos de fragmentación, estallidos nacionalistas y religiosos, que dislocan las entidades políticas existentes.

Pero dicho esto, a nosotros nos interesa cen- trarnos en una de las dimensiones fuertes del mundo de hoy: la mundialización o globalización, entendiendo que más que un mundo cerrado dibuja un mundo en transición, con graves contradicciones, hacia una nueva época.

El mundo de hoy, más que una geografía, es un mapa económico. El mercado financiero mundial es prácticamente un hecho, y no hay fronteras para la colocación de valores: unos cinco billones de dólares dan la vuelta al mundo cada veinticuatro horas. Por otra parte, puede decirse que de las cien unidades económicas más poderosas, la mitad son naciones y la otra mitad compañías transnacionales. Precisamente, las innovaciones en el ámbito de las telecomunicaciones han favorecido el crecimiento de las empresas transnacionales, la fusión de capitales y de recursos técnicos. Asimismo, el desarrollo de la robótica y de las nuevas tecnologías permite a las grandes compañías una mayor independencia respecto de la mano de obra y una marginación del trabajo de amplias masas de población.

No cabe duda que la dependencia de las economías locales respecto a la economía global es cada vez más creciente. Los países se sienten demasiado pequeños como para afrontar solos los desafíos para sobrevivir en un mercado mundial cada vez más competitivo e interrelacionado, de manera que cs un fenómeno generalizado el intento de formación de bloques o mercados regionales (Unión Europea, Tratado de Libre Comercio, Mercosur, Mercado Común Centroamericano, Asociación de Estados Caribeños...). No obstante, se observa una distancia entre los objetivos declarados de estas alianzas y los efectos reales. En síntesis, podemos decir que tratan de allanar el camino a los capitales, de la mano de una apuesta incondicional por el mercado y las políticas neoliberales.

La mundialización de la economía se da en el marco de una hegemonía del sistema capitalista tras la caída del llamado socialismo real. Incluso, países como China, Vietnam y Cuba no dudan en recurrir a los incentivos que produce la economía de mercado para salir del subdesarrollo (liberando sus mercados, atrayendo inversiones extranjeras...). Se consolida así un sistema global que toma sus decisiones en los mercados, y se empeña en construir espacios financieros y de consumo que compitan con la soberanía de los estados. Por otro lado, este sistema entiende de eficiencia pero es un ignorante en equidad. 
Sin embargo, aunque la mundialización se presenta como un triunfo del libre mercado a escala planetaria, lo cierto es que unos pocos centros de poder toman las grandes decisiones y regulan el comercio de acuerdo con sus intereses. Los países ricos imponen el libre comercio en los productos en los que tienen ventaja (debido a sus tecnologías) y restringen el comercio de aquellos productos que los países del sur pueden producir de la manera más competitiva. Hay un buen ejemplo en la agricultura europea, donde los gobiernos ponen límites a las importaciones y subvencionan a los productores locales como una forma de sostener su actividad, perjudicando claramente a los países pobres. Suspender las subvenciones incrementaría las posibilidades de exportación de los países pobres pero hundiría a la agricultura europea. ¿Deben aceptar los países ricos sacrificios en su bienestar de manera que aumenten las posibilidades de desarrollo de los países del sur? Nosotros decimos que sí.

La mundialización de la economía está en el puesto de mando de lo que se ha dado en llamar nuevo orden mundial, y que constituye una globalización que incluye a la política, la cultura, la seguridad. Efectivamente, del mundo bipolar hemos pasado a un mundo liderado por Estados Unidos, con el concurso de Japón y Europa, y la emergencia de China, que desarrolla procesos de globalización en una dirección que tiende a fortalecer el poder de las élites. Algunas de sus características son: el fortalecimiento de los poderes económicos, independientes de los poderes polílicos; la construcción de poderes supraestatales que dificultan el control de las sociedades y afectan a la soberanía nacional.

Hay un retroceso general de la democracia entendida como soberanía del pueblo, sustituida por el poder de instrumentos como el Fondo Monetario y el Banco Mundial, que dictan políticas a los gobiernos. Vivimos un vaciamiento democrático de las Naciones Unidas, organismo sujeto a los mecanismos de control y decisión de unos pocos países a través del Consejo de Seguridad.

Tendencia acusada a una mundialización de la economía en la que los bloques económicos regulan la competitividad, lo que lesiona incluso el llamado libre mercado (el GATT es un ejemplo de ello). El mercado actual es el mercado más monopólico de la historia económica de la humanidad. El mismo GATT reconoce que sólo el 7 por ciento del mercado mundial puede llamarse mercado libre; lo demás es un mercado entre compañías o un mercado administrado por convenios en y entre los estados.

Estados Unidos tiende a constituirse como gendarme militar mundial, algo probado por los hechos, con el consenso de otras potencias como Europa Occidental, Japón y Canadá (lo que no elimina la existencia de algunas contradicciones entre estas grandes potencias que luchan entre sí por áreas de hegemonía en los mercados). Una tarea que le da licencia para intervenir en cualquier continente, bien sea en nombre de los intereses globales de los países desarrollados, bien sea en nombre de la democracia. La reciente cumbre de la OTAN ha puesto de relieve quién manda en la alianza occidental y a quién beneficia.

Cada vez más, el norte ve en el sur un peligro migratorio, y como respuesta levanta fortalezas legales y alimenta la xenofobia y el racismo.

La revolución tecnológica, junto con cuanto positivo tiene en el campo de la salud, comunicación, transporte, y del conocimiento en general, se concibe principalmente en términos de productividad y crecimiento, pero genera desempleo, trabajo individualizado, la ruptura de los espacios de comunidad, la caída del asociacionismo de la gente, etc. La revolución tecnológica no es neutra. Va ligada al etnocentrismo y tiene fundamentos filosóficos de tipo lineal, de optimismo infundado, de visión ascendente de la historia, o sea, muy determinista.

¿Cuáles son las corrientes de pensamiento que actúan ante el mundo de hoy? Adoptando un criterio laxo, Celestino del Arenal distingue tres grandes grupos: conservador, reformista y radical. El primer grupo centra sus intereses en el fortalecimiento de estrucluras políticas jerárquicas - Grupo de los 7, Consejo de Seguridad de la ONU, OTAN...- desde las cuales pueda asegurarse la hegemonía y proteger su ofensiva económica neoliberal. Su comportamiento es contradictorio: por un lado está la insistencia en transcender el sistema estatal; por otra parte, el Estado sigue siendo para los conservadores de cada país rico un refugio de poder.

En este grupo de poder mundial está muy asentado el llamado realismo político. Es una línea de pensamiento que hunde sus raíces en la antigua Grecia y que alcanza su esplendor en la Edad Mo- 
derna europea de la mano de Maquiavelo y Thomas Hobbes. Hay tres principios en el realismo politi$c o$ : la tendencia humana hacia el conflicto, hacia el mal, es inmutable; la lucha por el poder es la inclinación natural de los grupos humanos; esta búsqueda del poder se realiza a través del Estado que se disputa con otros su mayor seguridad y mayor dominio.

Las consecuencias del realismo político, que es la política internacional de más éxito en Estados Unidos, y que tiene en esta época a Henry Kissinger como su gran divulgador, son las siguientes: (1) Los principios morales, al ser abstractos, no cuenIan en la política internacional. (2) La obligación de cada Estado es obtener el mayor poder político, siendo la cooperación algo subordinado a ese fin. (3) La hegemonía internacional de una nación, EsIados Unidos, es una aspiración justa. (4) La seguridad internacional se establece cuando el sistema internacional es una jerarquía en la cúspide de la cual se encuentran los más poderosos.

El segundo grupo, en el que se encuentra la socialdemocracia, se sitúa en una perspectiva global, pragmática, y se esfuerza en llamar la atención de los gobiernos sobre los problemas del mundo $y$ las soluciones a mediano y largo plazos. Trata de reunir las aportaciones tanto de gobiernos como de grupos privados y de organizaciones no gubernamentales. La propuesta no supone un cambio real de estructuras, sólo propone reformas destinadas a paliar las desigualdades. Los informes del Club de Roma insisten sobre el crecimicnto demográfico, el agotamiento de recursos y alimentos, en la polución. El esfuerzo general de los reformistas es hacia la democratización del orden mundial.

El tercer grupo, el de los radicales, no cree en la democratización porque considera que no hay democracia que democratizar. Su idea general es la del cambio real de las estructuras mundiales. Hay distintas corrientes pero un universo de preocupaciones comunes: (1) Valores acerca de la guerra y la paz, el bienestar económico, la justicia social, la democracia, los derechos humanos y el equilibrio ecológico. (2) Interés en describir, evaluar y proyectar las tendencias más importantes de la actualidad, como el crecimiento demográfico, el desarrollo tecnológico, el agotamiento de los recursos, la polución ambiental y la carrera de armamentos. (3) Desarrollo de referentes alternativos de orden futuro. (4) Selección de posibles modelos futuros más deseables. (5) Desarrollo de estrategias de transición con base en presiones a los poderes y cambios en los comportamientos individuales y colectivos, para superar las estructuras actuales.

En este último grupo nos encontramos las izquierdas más críticas. Hay en ellas dos inclinaciones: la primera que estima la necesidad de romper con la concepción estatocéntrica, superar el clásico paradigma del Estado y del poder, y abordar los problemas de hoy desde estudios y alternativas globales que se centrarían en problemas como acabar con el militarismo en el mundo, los derechos humanos, el equilibrio ecológico, la desigualdad económica, el hambre, la explosión demográfica; la segunda, que sin negar la necesidad de intervenir en el plano internacional, está convencida de la importancia de actuar y luchar por el poder en los estados. Considera que no se debe caer en una concepción cerrada de sociedad mundial que dejaría a la izquierda inerme, sumida en un complejo de impotencia ante la debilidad para influir en alteraciones globales y en las instituciones más poderosas.

\section{Pensar y actuar local y mundialmente}

Los pensamientos fraccionarios, localistas, que trocean todo lo que es global, ignoran la complejidad y el contexto planetario. Pero no basta con blandir la bandera de lo global: hay que asociar los elementos de lo global en una articulación que organiza mentalmente lo complejo; lo global tiene como contexto lo particular.

Debemos pensar local y mundialmente de manera simultánea. En realidad, ésta la única manera de desarrollar: un pensamiento radical que vaya a la raíz de los problemas; un pensamiento multidi- 
mensional; un pensamiento que conciba la relación entre el todo y las partes, como se da por ejemplo en la ciencias ecológicas; un pensamiento que considere la relación entre lo social, la economía, lo cultural, la política, lo nacional; un pensamiento que se reconozca siempre inacabado y negocie con la incertidumbre, particularmente en la acción, pues no hay acción sin lo incierto.

Así, pues, como bien afirma el pensador francés Edgar Morín, si lo global se vuelve abstracto cuando olvida las partes, lo local es igualmente abstracto cuando se aísla del contexto general. De modo que el pensamiento radical es un ir y venir de la parte al todo y del todo a la parte.

Para Morín hay cinco lases secuenciales en esta dialéctica del pensar y actuar local y mundialmente: (1) concienciación, (2) organización-relación, (3) no cooperación con el orden mundial, (4) confrontación-lucha contra la dominación y (5) redes para el asedio perpetuo al neoliberalismo.

El mundo de hoy reclama como nunca la apertura, la comunicación, el intercambio y el debate entre gentes radicales. No sería comprensible que micntras las fucrzas cconómicas y políticas predominantes mantienen cada vez lazos más estrechos para intervenir en el mundo como un escenario global, la izquicrda radical diera la espalda a este hecho y vivicra sin reconocerse. Además, hay que tener en cuenta que en las relaciones internacionales de hoy, los poderes políticos y militares utilizan habitualmente lo que se llama la teoría de los juegos. Esta teoría tiene dos líneas de aplicación. Una muy conocida es la suma-cero que se basa en el principio de que en un conflicto tiene que haber un vencedor y un derrotado; uno gana todo, el otro lo pierde todo. La suma-cero se aplica brutalmente a Cuba y a todos los movimientos de liberación que constituyen una amenaza para la ideología y los intereses conservadores. La otra línea de aplicación es la suma-no-cero, que supone negociar entre las partes en conflicto cuando conviene a la estrategia de los grandes poderes. En resumen, la teoría de los juegos que fue consagrada por Morgenstern y Neumann, en 1944, funciona en la política internacional como una partida de ajedrez, un cálculo racional que estudia todas las jugadas posibles del adversario para darle respuestas contundentes.

Lo que he querido decir es que mientras la izquierda permanezca fragmentada, dispersa, los poderes que manejan el mundo viven para conspirar y derrotar a las izquicrdas, y lo hacen sin descanso.

Así, pues, en cierto sentido es bueno recuperar la mística de un internacionalismo dispuesto a dejar jirones en otras partes y en otras aventuras libertarias. Pero es bien cierto que el internacionalismo de ayer debe ser revisado. 